\title{
THE RELATIONSHIP BETWEEN OCCUPATIONAL STRESS BURNOUT AND JOB PERFORMANCE AMONG TEACHERS IN BASIC EDUCATION SCHOOLS IN MUSCAT
}

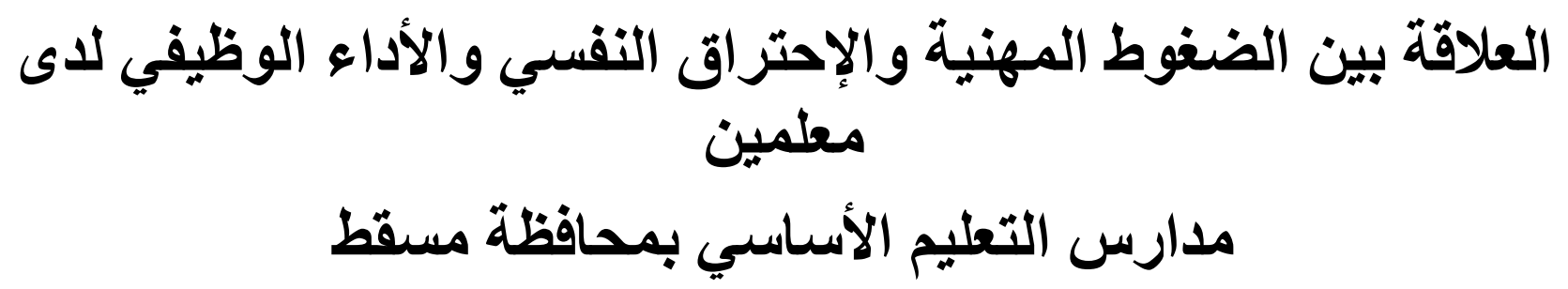

سلوى خليفه حمد الوحشي

Salwa Khalifa Hamed Alwahshi ${ }^{*}$, Nik Ahmed Hisham ${ }^{2}$ and Fatmir Sheikho ${ }^{3}$

${ }^{1} \mathrm{Ph}$.D. Candidate at the Department of Psychology, Faculty of Education, International Islamic University Malaysia (IIUM); salwa.alwahshi@moe.om

${ }^{2}$ Prof. Dr. at the Faculty of Education, International Islamic University Malaysia (IIUM);

nikahmad@iium.edu.my

${ }^{3}$ Dr., Senior Lecturer at the Faculty of Education, International Islamic University Malaysia (IIUM);

fatmir@iium.edu.my

${ }^{*}$ Corresponding Author

\begin{abstract}
The aim of the research is to discuss the relationship between psychological stress, burnout and the job performance of teachers. The researcher prepared a measure of psychological burnout, after referring to the literature and some measures of psychological burnout, including the Maslash scale of psychological combustion, which was adopted by many studies. A psychological stress scale was also developed, where the researcher reviewed the teachers 'psychological stress scale (1989). The researcher used the descriptive "relational" approach. The research sample consisted of (200) male and female teachers distributed in (10) schools for males and females. The study concluded the following results: There is a correlation between occupational stress and the total dimensions of burnout at the level of $(0.01)$. The study also found that there is no statistically significant relationship between occupational stress and job performance. Also, there is no statistically significant relationship between burnout in its four dimensions and the job performance of the teacher. It also became clear through the study that there is no statistically significant relationship between the physical dimensions of combustion and the job performance. The study also found that there were no differences between male and female teachers with regard to total burnout. Despite that, there is a difference between the two averages, which suggests that there are differences in males that they are less burning than females.
\end{abstract}

Keywords: psychological stress, burnout, job performance, basic education teachers. 


\section{الملخص}

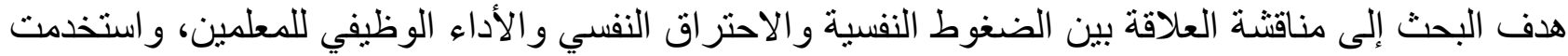

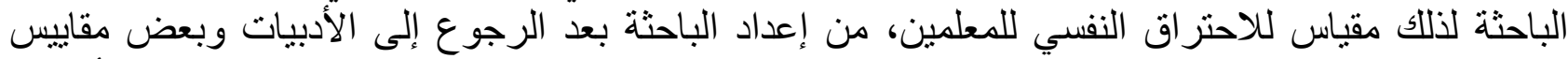

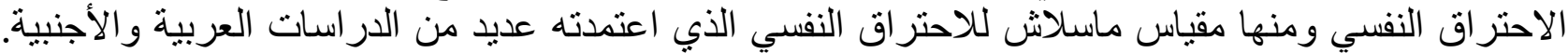

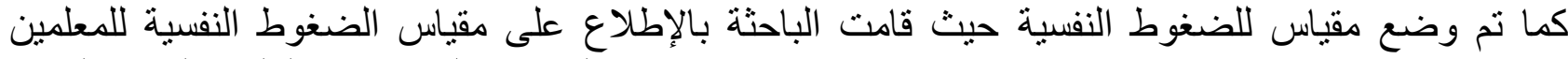
(1989) و وجدت ضرورة وضع مقياس حديث يتلاءم مع مستجدات العصر و المستجدات العلمية الحديثة لقياس

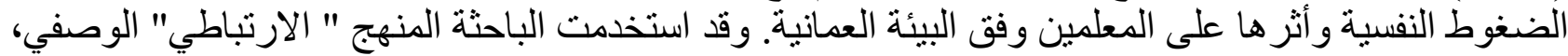

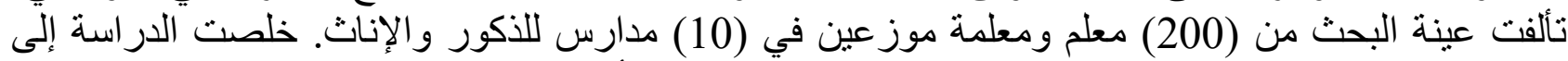

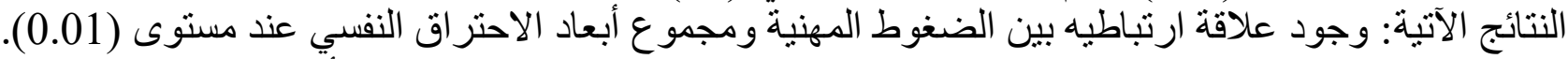

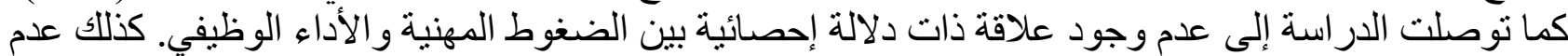

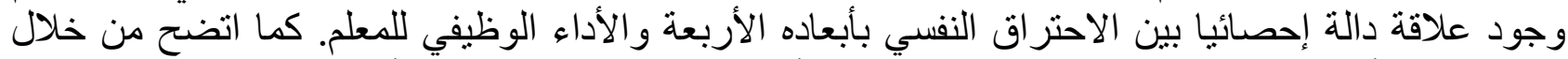

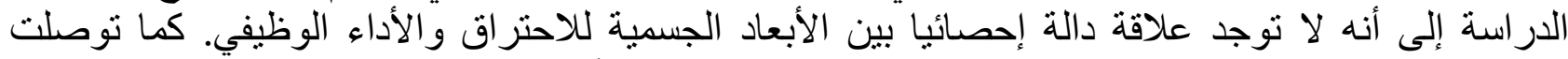

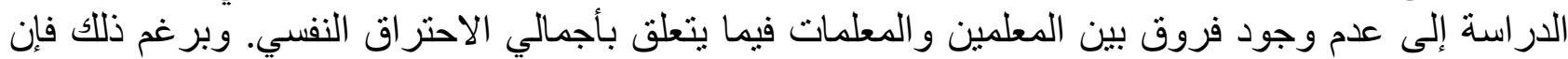
هناك فرق بين المتوسطين مما يوحي بوجود فروف بروف لدى الذكور بأنهم أقل احتر اقا من الإناث. كلمات مفتاحية: الضغوط النفسية، الاحتر اق النفسي، الأداء الوظيفي، معلمي التعليم الأساس.

\section{المقدمة :}

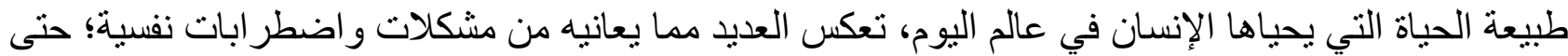

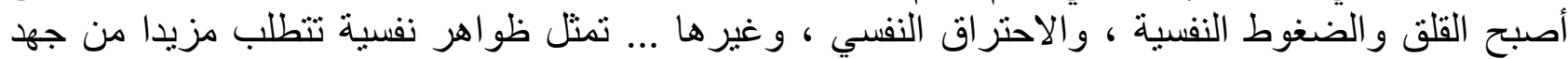
الباحثين وتفكير هم ؛ بهدف الكثف عن طبيعة كل منها، وتحديد مسبباتها ، وكيفية تفادي آثار ها السلبية. فنتيجة

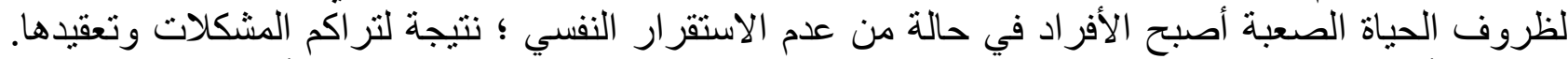

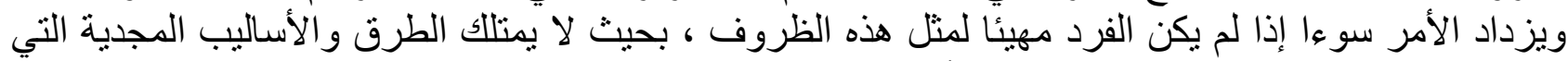

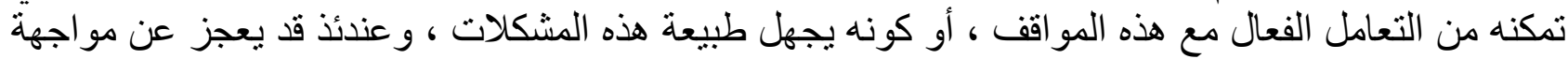

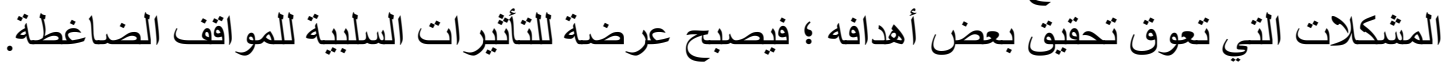
و إذا كان المجتمع المدرسي صورة من المجتمع الإنساني ؛ فإن المعلمين__إضافة إلى المشكلات الاجتماعية

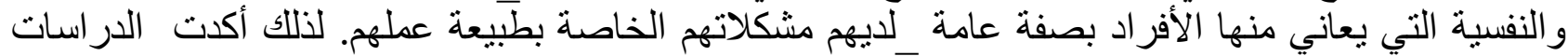
انتشار ظاهرة الاحتر اق النفسي بين المعلمين وآلمعلمات بنسبة مرتفعة تر اوحت بين (77\% إلى مراد و أنور عبد الغفار ، 1991) و وحسب تصنيف منظمة العمل الدولية " تعد مهنة التدريس من أكثر مجالات

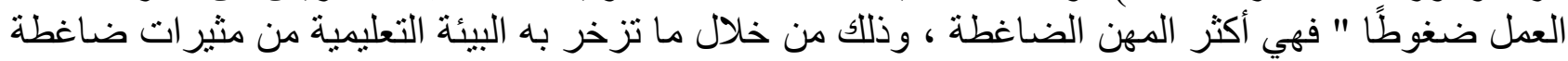

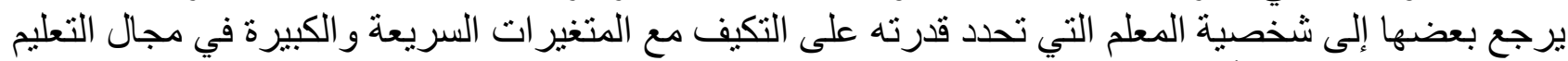

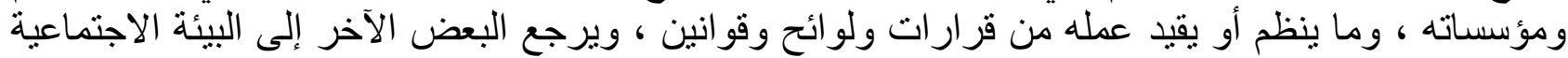
الخارجية التي يعيش فيها المعلم ، ومدى تقدير ها لدون الدور المعلم ولأهمية التعليم .

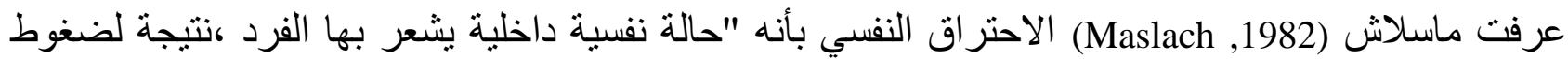

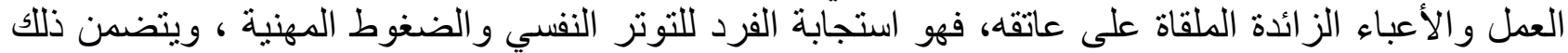

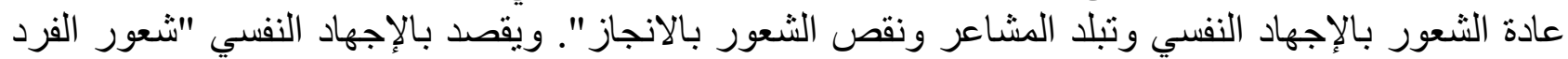

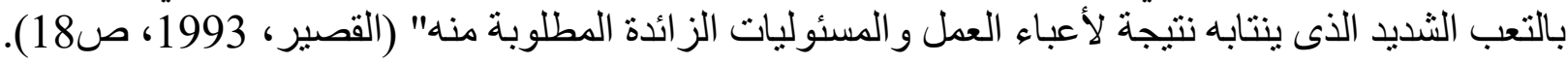

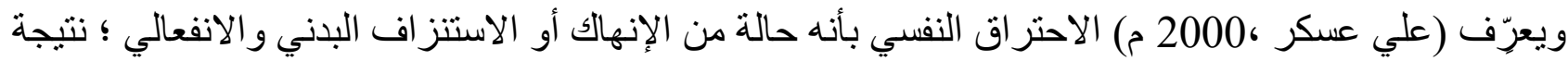

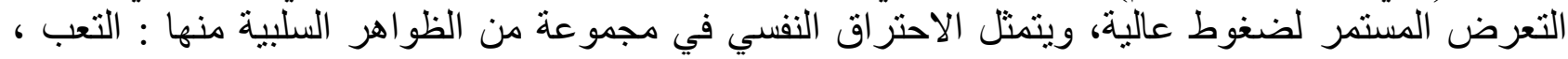

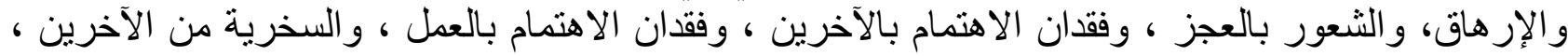

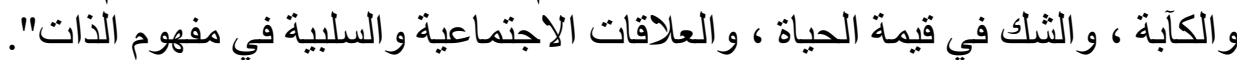


أما الضغط النفسي: فهو "إدر الك المعلم لعدم قدرته على مواجهة أحداث أو متطلبات مهنة التدريس ؛ والتي تشكل

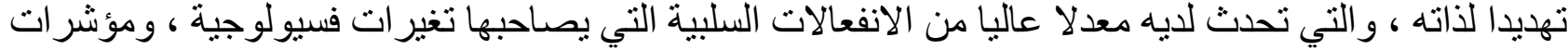
سلوكية كرد فعل على تللك الضغوط ، والته والتي تستلزم نوعا من إعادة التوافق عند المعلم" (السيد السمادوني،

و إذا كان من المهم التصدي لظاهرة الضغوط النفسية للعمل عامة، فالتصدي لضغوط مهنة التدريس أكثر أهمية ،

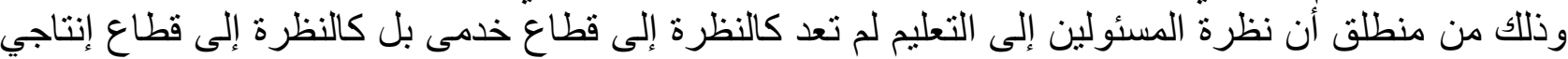

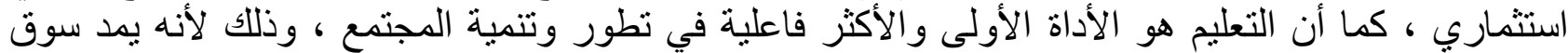

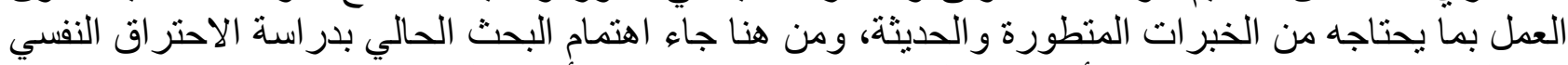
لاى المعلمين في مدارس التعليم الأساسي بسلطنة عمان ، و وعلاقة ذلك بأدائهم الوظيفي. إنَّ عمل الباحثة الحالي في سلك التدريس ومعايشتها للو اقع اليومي في المدرسة؛ من الأسباب التي دفعتها لتناول هذا الموضوع بالبحث و الدراسة، في ضوء ما يشهده التعليم في عمان من توسع شامل وكبير في مختلف

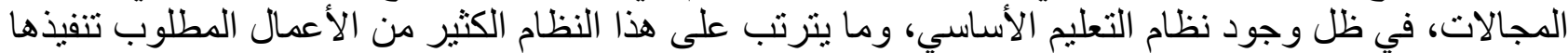

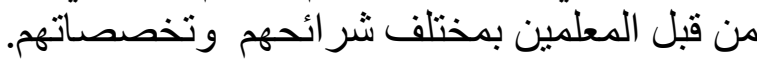

وتعد هذه الدر اسة من الدر اسات القليلة في علم النفس التربوي التي تناقش ضغوطات مهنة التعليم والاحتراق النفسي للمعلم.

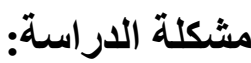

في ظل تطور النظام التعليمي في سلطنة عمان، ووجود نظام التعليم الأساسي الذي بتضمن العديد من الأعمال

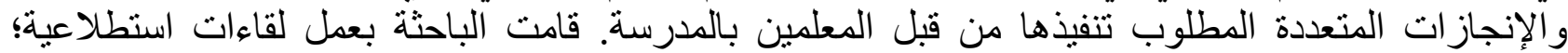
لمعرفة مدى وجود الضغوط المهنية لدى المعلمين، وما أثبتته هذه اللقاءات وبنسبة كبيرة من وجود احتراق

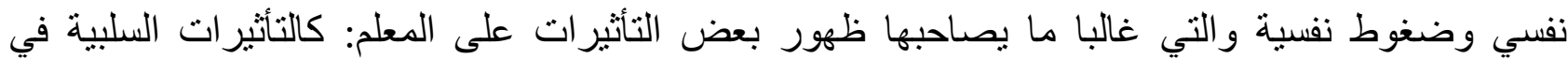
اتجاهاته و علاقاته داخل وخارج المدرسة ، ونقص قدرته على العمل والأداء؛ حيث يشعر باستنفاذ الجهد ، و التعب، والإجهاد النفسي والبدني ؛ و الذي يؤدي بلدوره إلى إلى الاحتراق النهي النفسي ؛ مما قد يؤدي إلى أن يقع المعلم

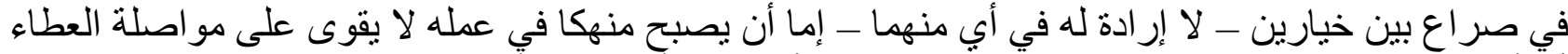

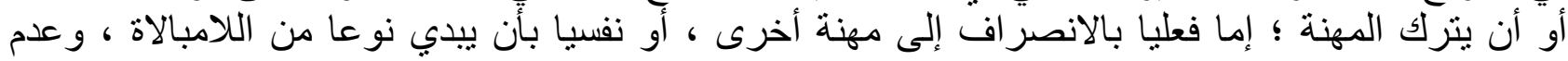
الا هتمام ، و إهمال متطلبات مهنة التدريس.

و هو ما لاحظته الباحثة على بعض المعلمين، ممن بظهر عليهم أثر المعاناة من الضغوط المئه المهنية المستمرة،

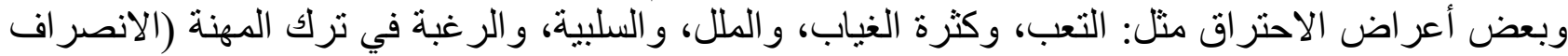

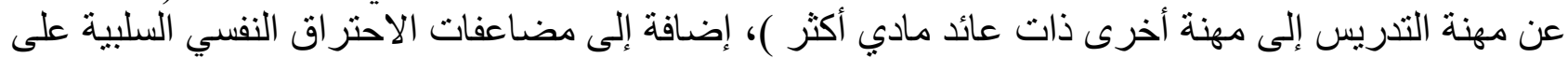

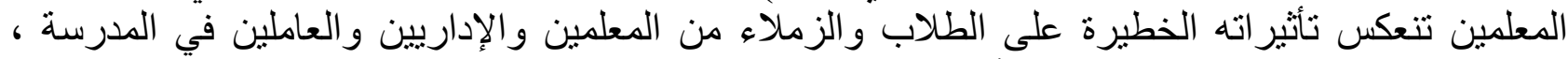

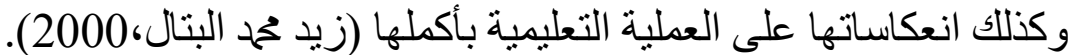

وقد أجرت الباحثة مقابلة مقننه مع ثلاثة من المشرفين التربويين بمديرية مسقط، وذللك للتعرف على آلى آرائهم و ولاحظاتهم حول ظاهرة الاحتر اق النفسي للمعلمين و أثر ها على الجنسين، وتعرفت التهن الباحثة على الآتي: أ. أكد المشرفون أنَّ الاحتر اق النفسي أصبح ظاهرة في هذه المهنة، فلكل مهنة متاعبهاو مشاقها، ومهنة التعليم

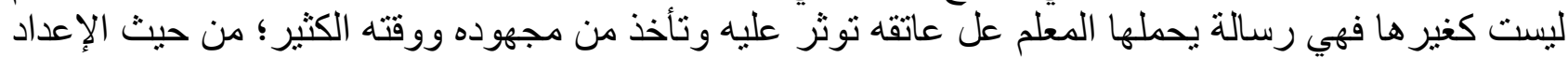

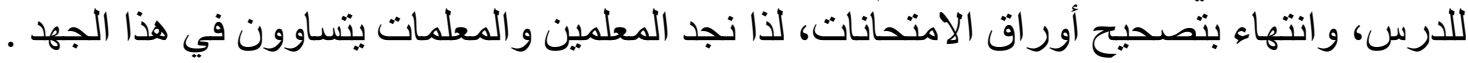
ب. أتفق المشرفون أنهم غير راضين عن كيفية إعداد المعلم لهذه المهنة فلم يتلقى التدريب الكافي ولا الأعداد

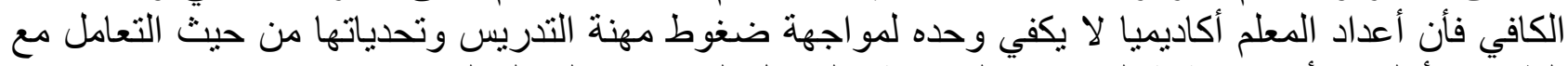

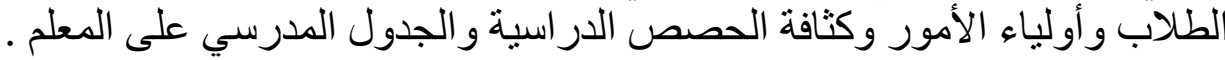
ت. أضافو ا أن لوصول المعلم لحالة الاحتر اق أسباب كثيرة منها: ما يتعلق بمكان العمل حيث يتم تعينهم في أمكان 
نائية و لا سيما للمعمات ، ومنها ما يتعلق بحياتهم الاجتماعية حيث يكاد المعلم لا يجد وقتا كافيا للقيام بواجباته

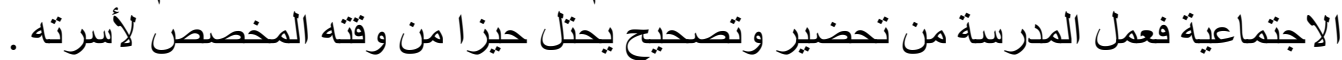

ث. ثويرى المشرفون أن المعلمين و المعلمات يعانون من الاحتر اق النفسي وضغوط المهنة دون فرق بينهم و كثير

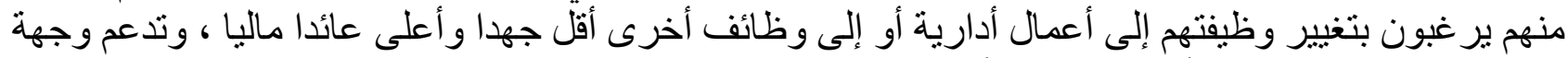
نظر المشرفين التربويين رأي الباحثة في أهمية الدراسة الحية الحالية .

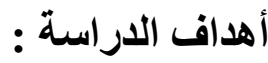

أ. التعرف على طبيعة العلاقة بين ضغوطات مهنة التدريس و الاحتراق النفسية من خلال مقياس الاحتراق ومقياس الضغوط النفسية للمعلمين . ب. التعرف على طبيعة العلاقة بين ضغوطات مهنة التدريس و الأداء الوظيفي للمعلمين . ت.در اسة مدى وجود فروق فردية بين المعلمين تجاه ضغوطات المهنة تعزى لمتغير النوع ، أو الخبرة ، أو أو أوسئ

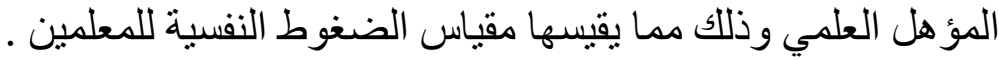

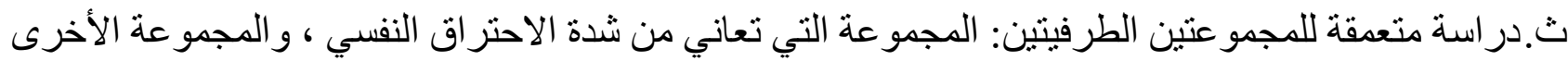
التي تقل عندها نسبة الاحتر اق وفق مقياس الاحتر اق النفسي ـ النقين

الار اسات السابقة:

أولاً. دراسات تناولت الاحتراق النفسي والمتغيرات الايموجرافية: الجنس والعمر وسنوات الخبرة والحالة الاجتماعية:

دراسة الباحثين (1988) Agaliotis, \& Platsidou, ركزت على الاحتراق النفسي والرضا الوظيفي، ومصادر

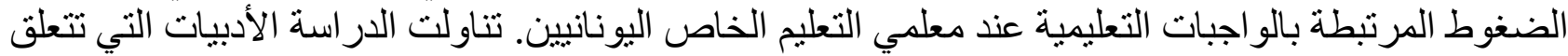

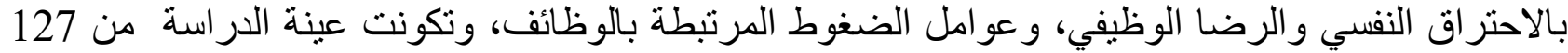

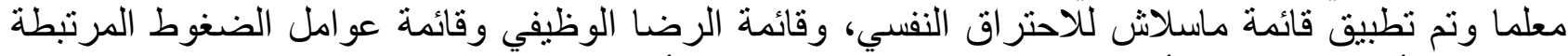

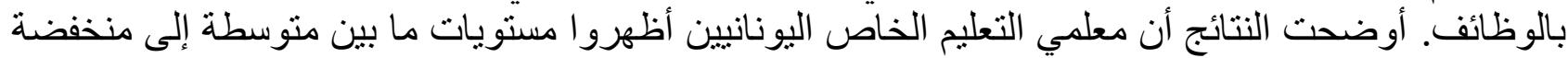

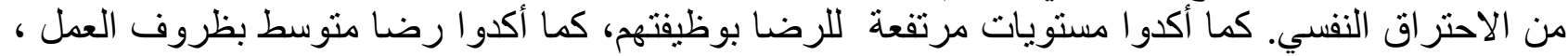

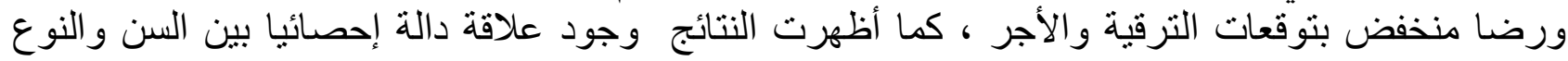

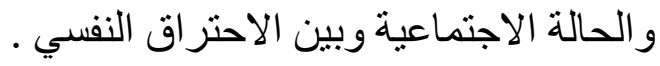

دراسة قيلانج وجل (2003): تناولت ضغوط مهنة التدريس والاحتراق النفسي وعلاقة المعلم بطلابه من

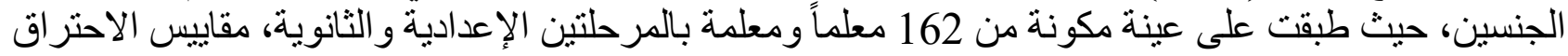

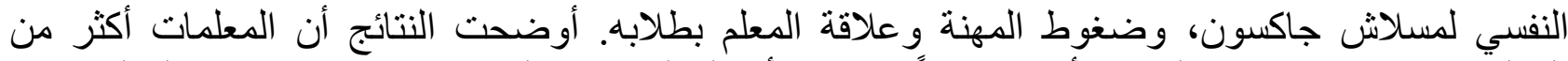

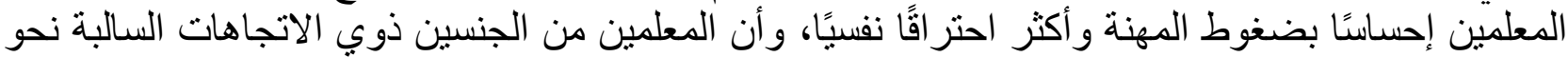
الطلاب هم الأكثر معاناة من ضغوط المهنة المهنة وأكثر احتر اقًًا نفسيًا.

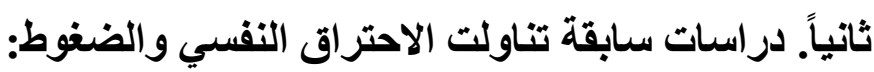

دراسة Kokkinos, constantions (2007 عو امل الضغوط الوظيفي و الشخصية و الاحتر اق النفسي لدى معلمي

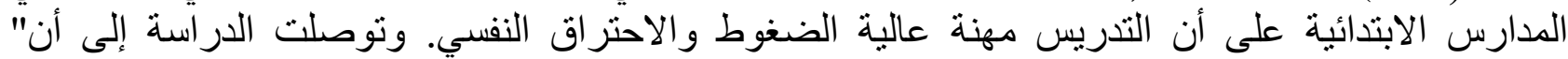

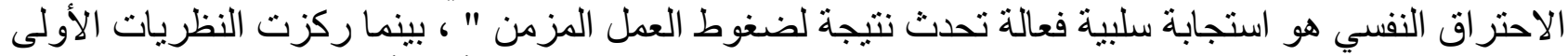
للاحتر اق النفسي بشكل حصري على افى عو امل الضغوط المرتبطة بالعمل ، إلا أن الأبحاث الحديثة تنتبى الاتجاه

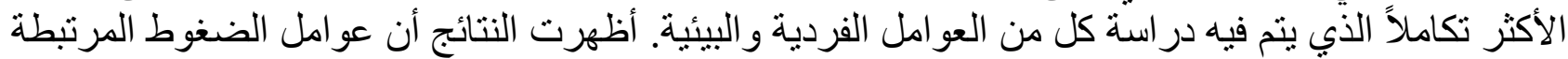

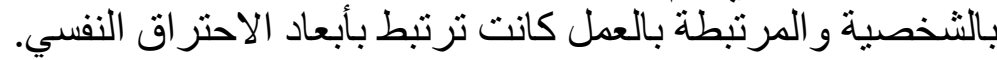
دراسة للباحث (2004) هدفت إلى بحث مدى انتشار الاحتر اق النفسي، واختبار النموذج الهيكلي

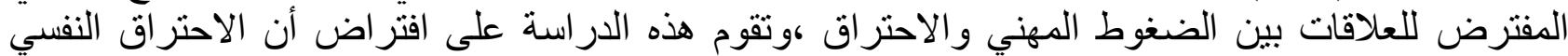


يتطور عندما تكون متطلبات الوظائف عالية وموارد الوظائف محدودة . اعتبرت الدراسة أن متطلبات العمل

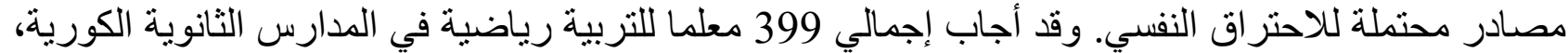
وقدموا معدل استجابة كلي 80\% .كثفت نتائج تحليل البيانات عن وجود احتراق نفسي لمعلمي التربية

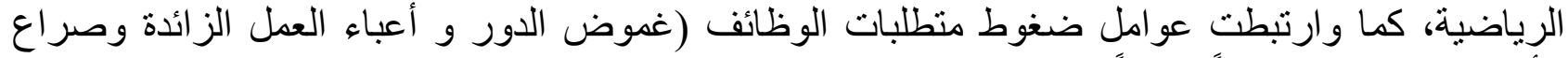

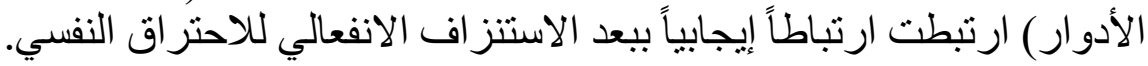

ثالثاً: دراسات سابقة تناولت مصادر الاحتراق النفسي والضغوط

دراسة ساندرز وواتكنز, (2003): تناولت ضغوط الحياة وأسلوب حياة المعلم وعلاقتها ، بضغوط مهنة

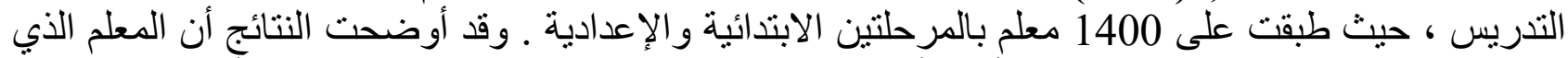

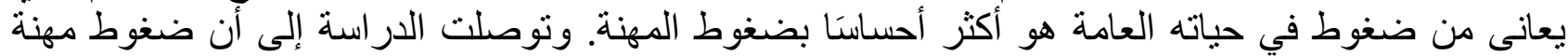
التدريس ترجع لمصادر أهمها : العائد الاقتصادي للمهنة وعنئ وعلاقة المعلم بطلابه وتلاميذه .

دراسة دنيهام ستيف (2003): تناولت استقالة المعلمين من مهنة التدريس، وقد بحث فيها أسباب استقالة

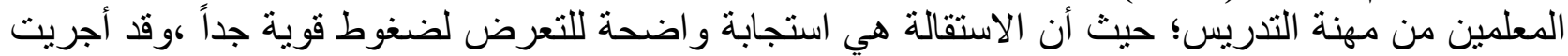

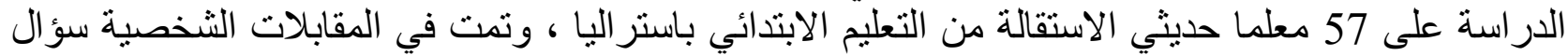

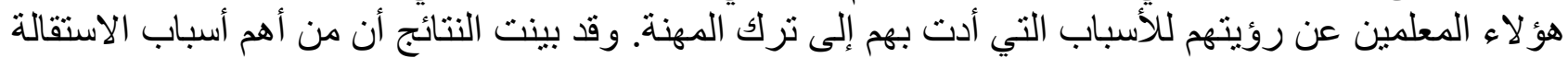
كانت وصول المعلم إلى نقطة حرجة في مسيرته فى مهنة التدريس تللك التي يعجز المدرس فئها فئا عن مسايرة

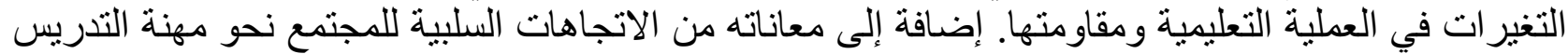

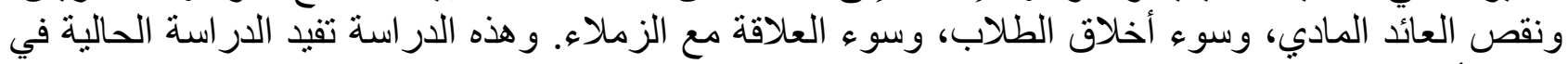

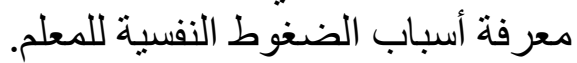

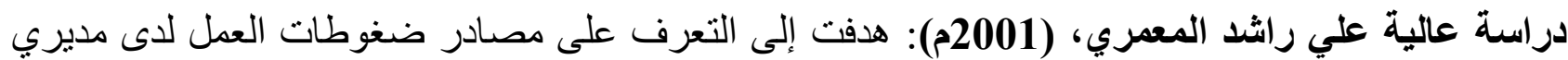

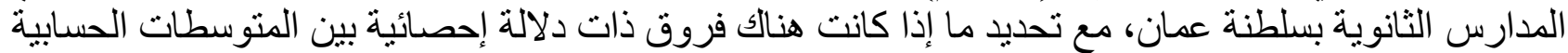
لأبعاد مصادر ضغوطات العمل وفقا للجنس والعمر والخبرة الإدارية. ومن أهم النتائج التي توصلت إليها

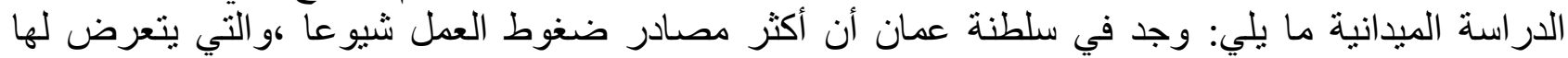

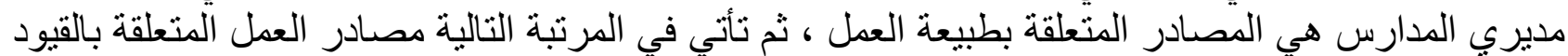

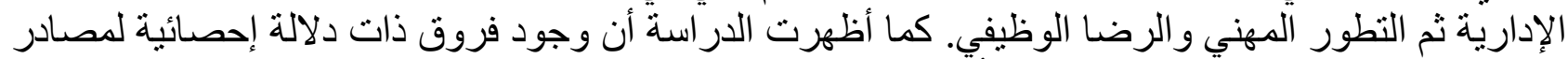

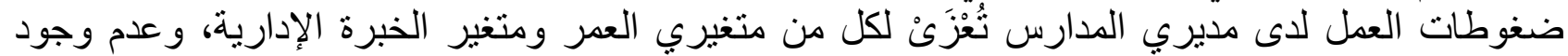

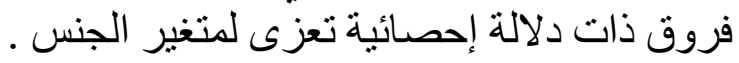

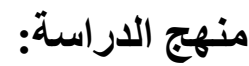

استخدمت الباحثة المنهج " الارتباطي" الوصفي لمناسبته لطبيعة البحث. مجتمع الاراسة: شمل مجتمع الدراسة 34589 معلما ، منهم (56\%) من الذكور ، (44\%) من الإناث في مدارس التعليم الأساسي بمحافظة مسقط وقد تم اختيار مدارس العاصمة لتكون منها عينة الدارسة الحالية . عينة الدراسة: تألفت عينة البحث من (200) معلما ومعلمة موزعين على (10) مدارس منها ( 5 ) مدارس للأكور و ( 5 ) مدارس للإناث، وتم اختيار تللك المدارس بكتابة مجمو عة من مدارس الذكور ومجمو عة من مدارس الإناث ، ثم الاختيار العشوائي لخمس مدارس من كلا الجنسين ، وذللك لضمان عشو ائية الاختيار لعينة الدر اسة.

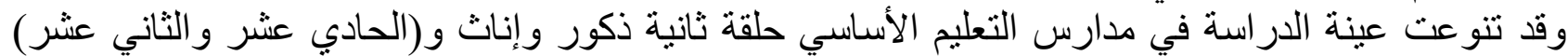

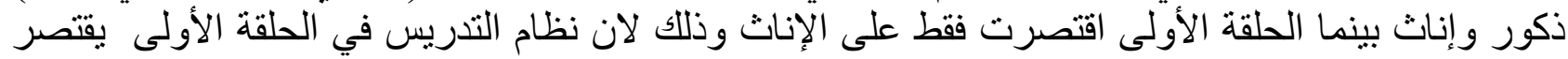
على المعلمات. ويتجانس أفراد العينة في: (الجنس، المؤهل العلمي، الوظيفة الحالية، سنوات الخبرة، العمر، المرحلة التدريسية، الحالة الاجتماعية). 
ويرجع سبب اختيار الباحثة محافظة مسقط لتكون منها عينة الدر اسة بسبب التتوع السكاني و التشابه في المستوى

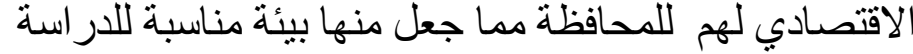

أدوات الدراسة : أدات

أولاً: مقياس الاحتراق النفسي للمعلمين (إعداد الباحثة)، بعد الرجوع إلى إلى بعض مقاييس الاحتر اق النفسي؛ منها

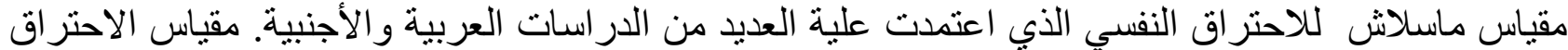

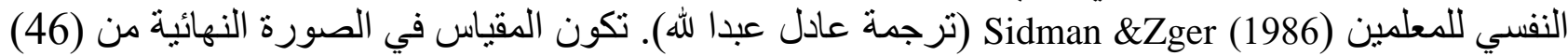
فقرة مقسم إلى: (10 ) بنود لقياس البعد الجسي،، (13 ) بندا لقياس البعد النفسي، (10 ) بنود لقياس البعد الاجتماعي، (13) بندا لقياس البعد المهني. وكما يلًي:

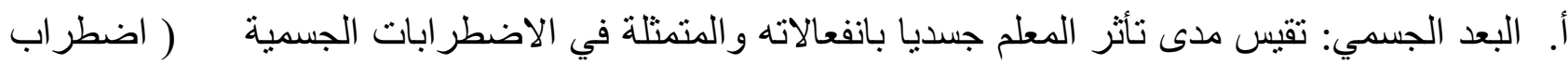
النوم و الصداع المتكرر و غير ها).وتكون الدرجة الصغرى (10) و الدرجة الدانة الكبرى (50).

ب. البعد النفسي: تقيس الانفعالات التي يمر بها المعلم في عملة متمثلة في ( الاكتئاب و الإحباطو التوتر ). وتكون

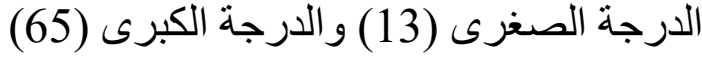
ت. البعد الاجتماعي: وهي تقيس مدى تأثثر الوضع الاجتماعي بالمعلم وعلاقة ب ( الزملاء والأسرة). وتكون

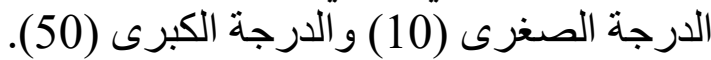

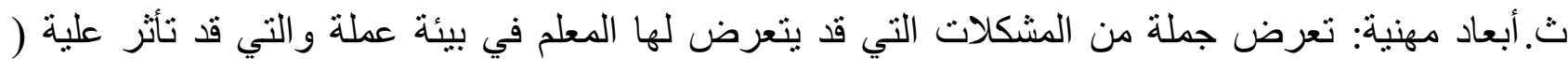

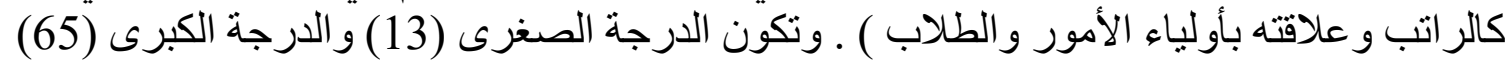
وتم تحديد المدارس المستهدفة لتكون منها عينة الدراسة ، وقامت الباحثة بالذهاب إلى مدارس المعلمات

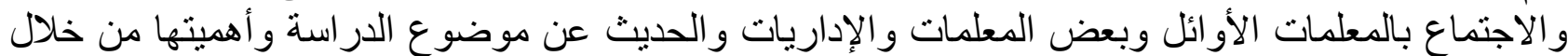

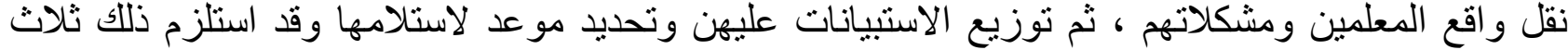

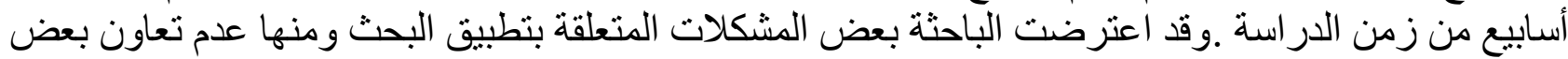

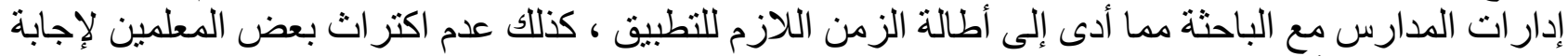

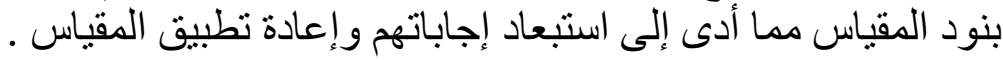
ثانيا: مقياس الضغوط النفسية ( إعداد الباحثة) تمت مر اجعة أدبيات الدر اسات السابقة وذلك لوضع مقياس حديث لقياس الضغوط النفسية و أثر ها على المعلمين وفق البيئة العمانية. قامت الباحثة بالإطلاع على مقياس الضغوط النفسية للمعلمين( 1989) وجدت الباحثة ضرورة وضع مقياس

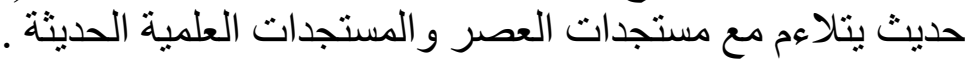
خطو ات إعداد المقياس:

مقياس الضغوط النفسية (1989): أعداد (طلعت منصور ، وفيو لا الببلاوي 1989). وضع مفردات المقياس: قامت الباحثة قبل وضع مفردات المقياس بدر اسة وفحص الكتب و المقاييس العربية و الأجنبية في هذا المجال و الاستفادة منها في وضع المقياس، منها: مسعود عبد الحميد حجو (2002)؛ عويد سلطان المشعان (2004)؛ محمد الصيرفى (2007).

وقد تم عرض المقياس أيضا على مجمو عة من المعلمات بالمدرسة بهدف أخذ رأيهن في المقياس ومدى إحاطته بجميع جو انب الضغوط النفسية للمعلمين ، وتم بعد المناقثة إضافة بعض المتغير ات الديمجر افية كمتغير الحالة الاجتماعية، و الوظيفة الحالية.

يتكون المقياس في صورة النهائية فتكون من (48) فقرة موزعة لعدة محاور تتعلق بالضغوط التي يعاني منها

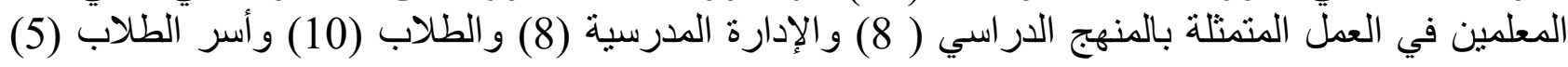


و الموجهون التربويون (5) و المجتمع (5) و الامتحانات (7). وتتكون الضغوط التي يواجها المعلم كالآتي:

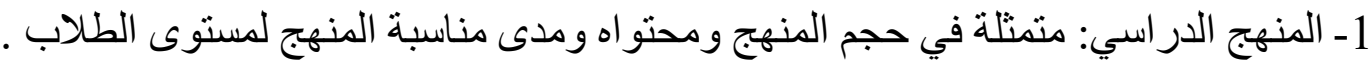
2- الامتحانات : منتنلة في كم الامتحانات التي تطالب الوزارة بها فيا

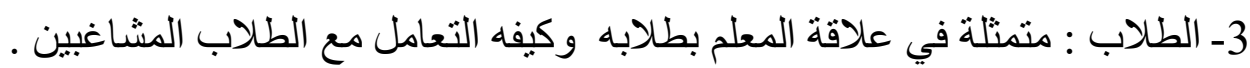

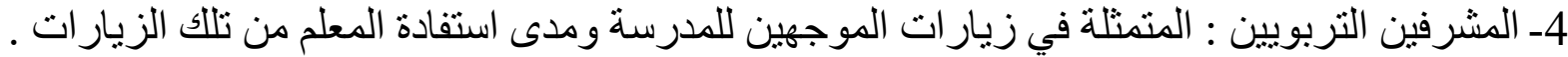
5- الإدارة المدرسية: متمثلة في علاقة المعلم بالإدارة الددرسية والأعمال الإدارية التي تطالبه بها 6- أسرة التلاميذ تتمثل في عدم تعاون بعض أسر التلاميذ مع المعلم ومتابعتهم لأبنائهر 7ـ المجتمع : المتمثلة في نظرة المجتمع لمهنة التدريس ور اتب المعلم

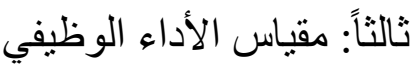

يتكون هذا المقياس من (48) فقرة تقيس أثر الضغوط المهنية على أداء المعلم ، ويتم الإجابة على القائمة بأخذ

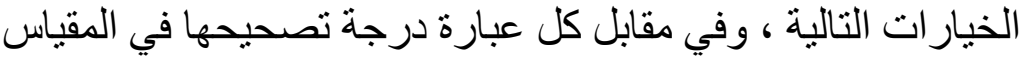
- يز عجني بشدة، ودرجتها 2 في تصحيح المقياس ـ لا يز عجني إطلاقا، ودرجتها 1 في تصحيح المقياس وبالتالي تكون الدرجة الصغرى 48، والدرجة الكبرى 96؛ فكلما كانت الدرجة أكبر كلما كانت دليلا على شدة

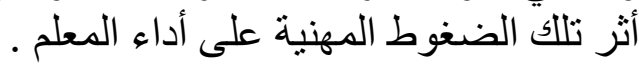
رابعاً: المقابلات الثخصية: (إعداد الباحثة) أجرت الباحثة مقابلة مقننه مع ثلاثة من المشرفين التربويين بمديرية مسقط في يوم الأربعاء

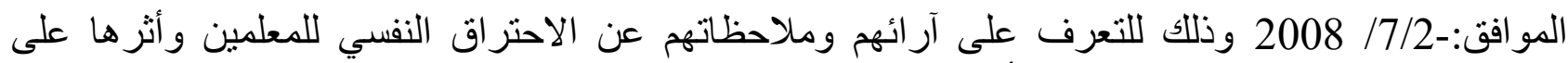

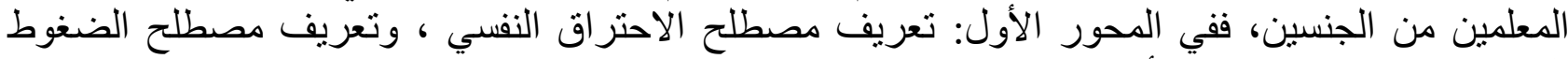

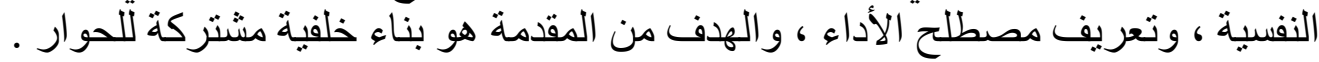
المحور الثاني: كيف يرتبط إعداد المعلم بالاحتراق و الضغوط والأداء المحور الثالث: كيف ترتبط مسئوليات المعلم بالاحتراق و الضغوطو والأداء الدحور الرابع: كيف يمكن للنظام التعليمي أن يوفر للمعلم ظروفا تجنبه التعرض للاحتراق النفسي والضغوط المهنية

الأساليب الإحصائية :للإجابة عن أسئلة الدراسة ، استخدمت الباحثة الأساليب الإحصائية الآتية :

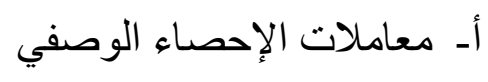

- معامل ارتباط بيرسون للتعرف على مدى وجود علاقة بين متغير ات الدراسة. ـ ـ معامل التباين الأحادي للتعرف على الفروق بين المجمو عات في متغير ات الدراسة

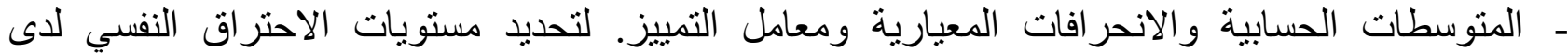
المعلمين العمانيين. بـ معاملات الإحصاء الاستدلالي: اختبار "ت" للعينات المستقلة للتعرف على الفروق بين المجموعات . أولا: الإحصاء الوصفي: الإحصاء الوصفي: يهذف إلى وضع تصور عام ، ورؤية واضحة للظاهرة ويوضح المتوسطات الحسابية 


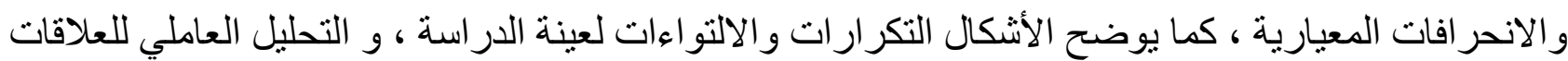
، ويشمل الإحصاء الوصفي لعينة الدراسة مقياس الاحتراق النفسي ومقياس الضغوط المهنية ومقياس الأداء الوظيفي.

ترثتب أبعاد الاحتراق النفسي: من أكثر أبعاد الاحتراق النفسي تأثير العلى المعلم البعد الاجتماعي في المرتبة

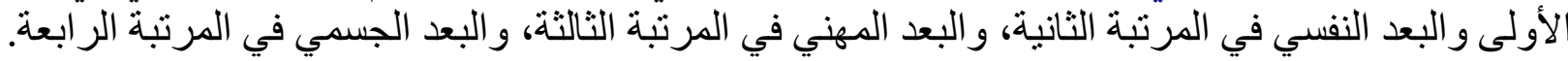
ترتيب أبعاد الضغوط المهنية: ركز هذا المقياس على الضغوط المهنية للمعلم ، ويلاحظ أن اكبر مصدر للضغوط المهنية للمعلم هو بعد أسر التلاميذ في المرتبة الأولى و بعد الطلاب في المرتبة الثانية و بعد الإدارة المدرسية

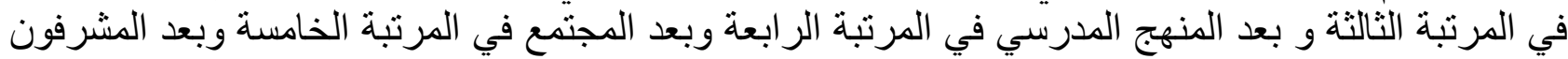

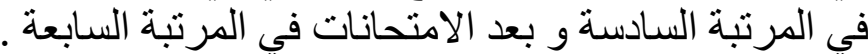

ترتيب أبعاد الأداء الوظيفي: ركز المقياس على رؤية المعلم لما بسبب له من إز عاجا يؤثر على أدائه، و يلاحظ

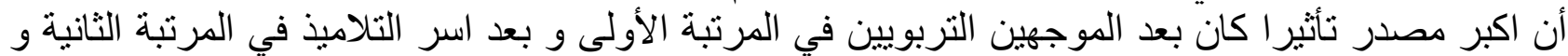

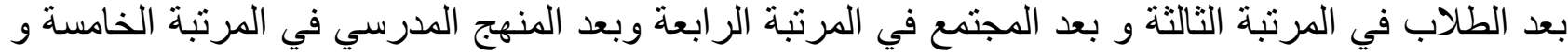
بعد الامتحانات في المرتبة السادسة وبعد الإدارة المدرسية في في المرتبة المبة المبة السابعة.

ثانيا: فروض الدراسة

الفرض الأول: "توجد علاقة دالة إحصائيا بين درجات أفراد العينة على مقياس الضغوط المهنية ومقياس الاحتر اق النفسي".

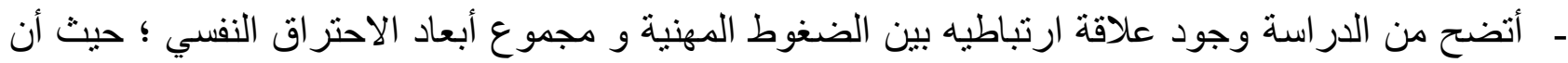
قيمة معامل ارتباط بيرسون (ر= 0.644) وهي دالة إحصائيا عند مستوى (0.01)

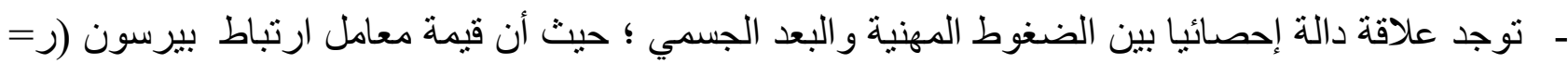

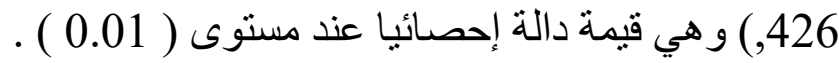
- ـ كما توجد علاقة دالة إحصائيا بين الضغوط المهينية والبعد النفسي للاحتراق النفسي؛ حيث أن قيمة معامل

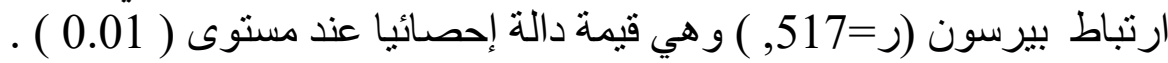

- توجد علاقة دالة إحصائيا بين الضغوط المهنية والبعد الاجتماعي للاحتراق النفسي ؛ حيث أن قيمة معامل ارتباط بيرسون (ر) 456,4* ) ) وهي قيمة دالة إحصائيا عند مستوى ( 0.01) .

- - توجد علاقة ارتباط دالة إحصائيا بين الضغوط المهنية والبعد المهني للاحتر اق النفسي؛ حيث إن قيمة معامل

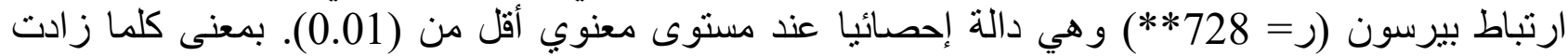

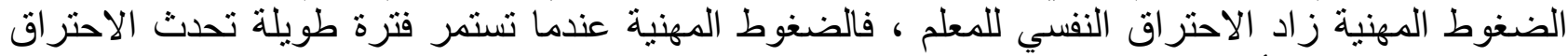

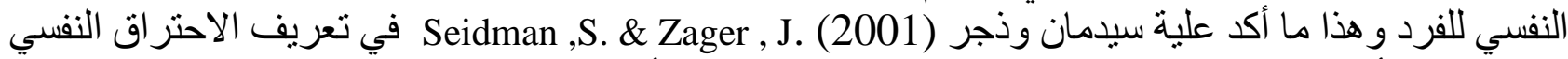

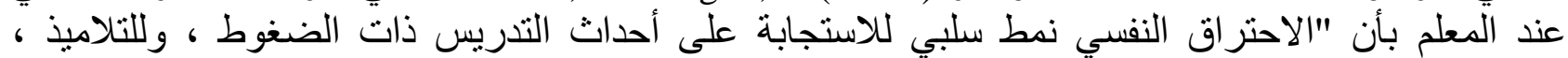
وللتدريس كمهنة بالإضافة إلى إدرالك أن هنالك نقصانا في المساندة والتأيد الذي يقدم للمعلم من جانب إدارة المدرسة.

وتفسر الباحثة هذه النتيجة اعنمادا على نظرية ( دورن وند، 1980) التي ربطت بين الضغوط التهي المهنية

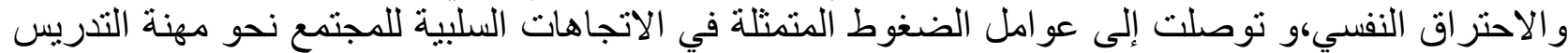

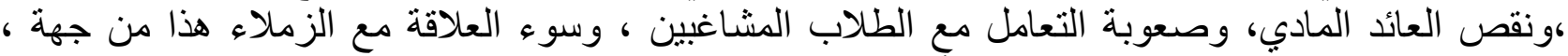

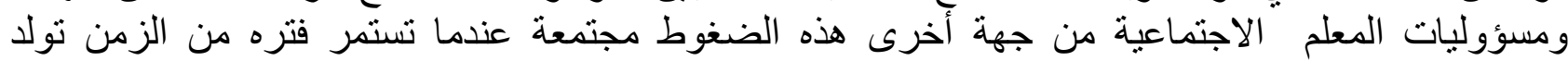
الاحتر اق النفسي للمعلم . التمعل

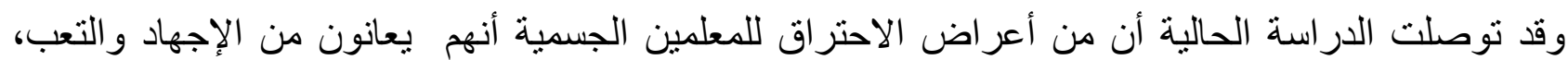
ويشعرون بالجفاف في الفم ، وشهيتهم للطعام غير جيده ، وترتبط الأبعاد الجسمية للاحتر اق بالضغوط الخئ المهنية . 
و الأبعاد النفسية للاحتر اق وهي حقي غير محفوظ في عملي ، ولا يشعرون بالسعادة أثناء وجودهم في المدرسة

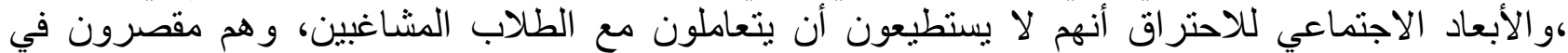

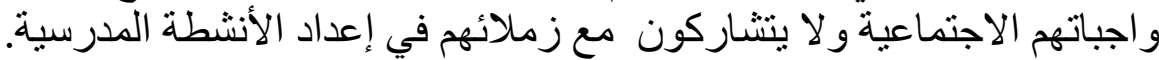

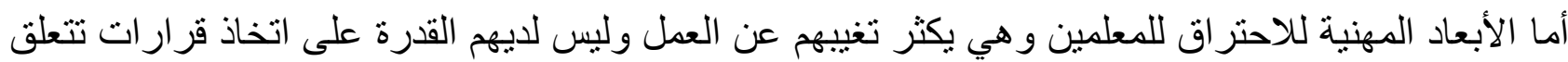

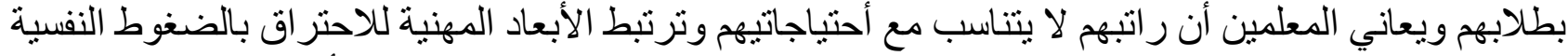

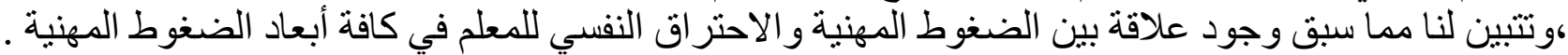

الفرض الثاني: "توجد علاقة دالة إحصائيا بين الضغوط المهنية والأداء الوظيفي للمعلمين ".

تم أعداد مقياس الضغوط النفسية والأداء الوظيفي في مقياس واحد وذللك لقياس مستوى الضغوط النفسية وأثر

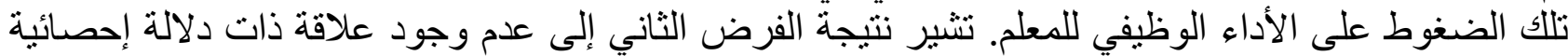

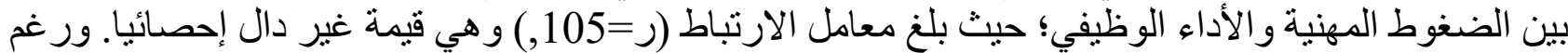

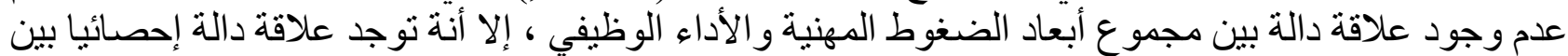

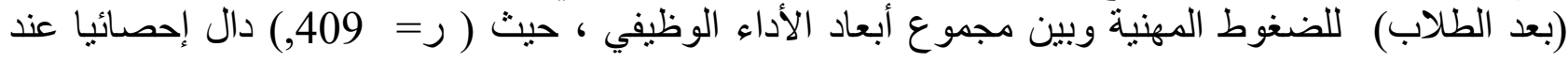

$$
\text { مستوى (0.01). }
$$

وقد اتفقت العديد من الدراسات على أن الضغوط المهنية في مهنة التدريس تؤثر على الدور التربوي للمدرسة

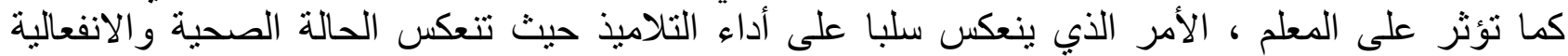
للمعلمين على تلاميذهم.

وتعزو الباحثة عدم وجود ارتباط بين الضغوط المهنية والأداء الوظيفي للمعلم؛ حيث توجد أعباء وضغوط مهنية

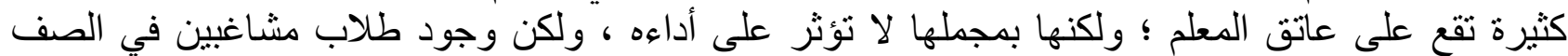

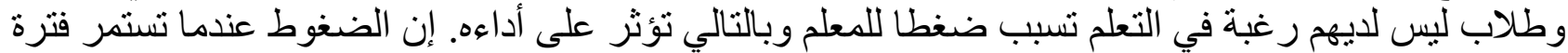

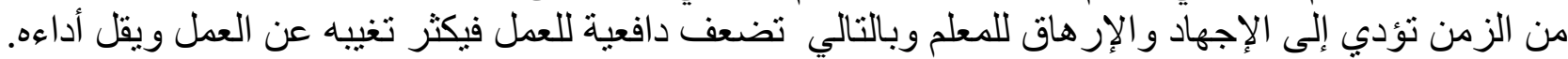

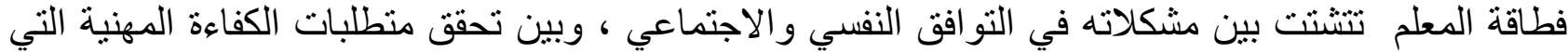

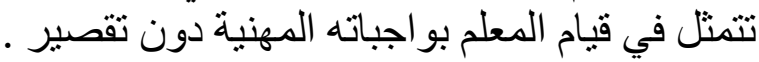
وقد توصلت الدر اسة الحالية إلى وجود ضغوط نفسية تقع على المعلم ومنها وجود أخصائي اجتماعي و احد في

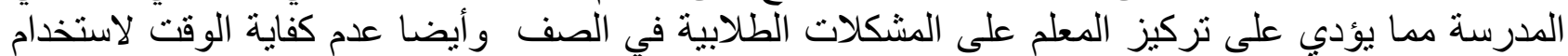

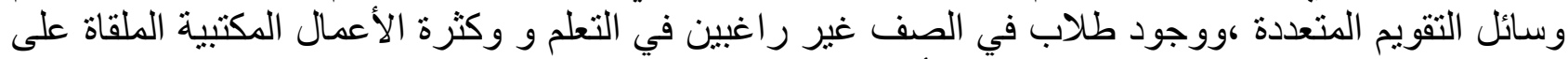

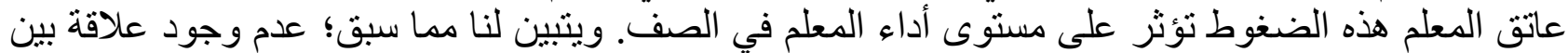

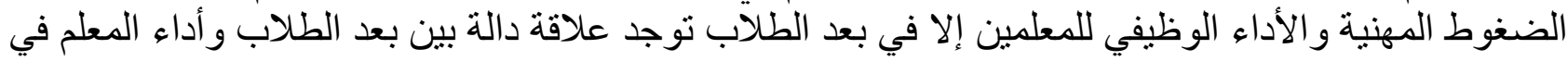

الفرض الثالث: "توجد علاقة دالة إحصائيا بين الاحتر اق النفسي والأداء الوظيفي للمعلمين". يتضح من الدر اسة عدم وجود علاقة دالة إحصائيا بين الاحتر اق النفسي بأبعاده الأربعة و الأداء الوظيفي للمعلم ؛

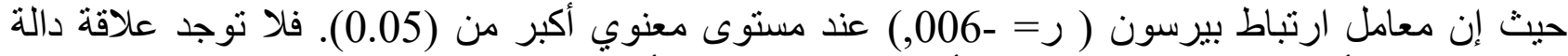

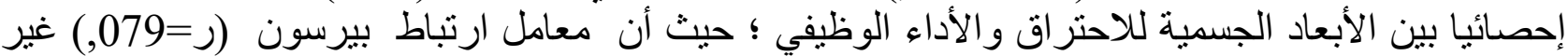
دال إحصائيا .

ولا توجد علاقة إحصائية بين الأبعاد النفسية للاحتراق النفسي والأداء الوظيفي ؛ حيث أن معامل ارتباط

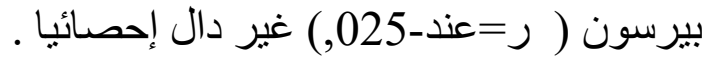

كما لا توجد علاقة إحصائية بين الأبعاد الاجتماعية للاحتر اق النفسي والأداء الوظيفي ؛ حيث أن معامل الارتباط

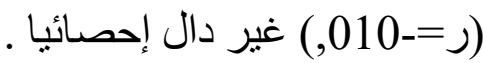

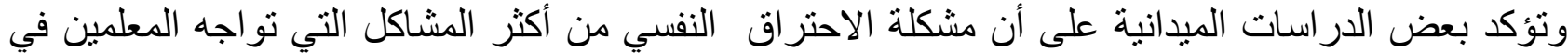
الوقت الحاضر فقد أشارت نتائج الدراسات الاستطلاعية التي قامت بهات التهات الجمعية الوطنية الأمريكية للتربية 
أن الآلاف من المعلمين الأمريكيين يتركون مهنتهم التدريسية نتيجة للاحتراق النفسي الذي يواجهونه (NEA)

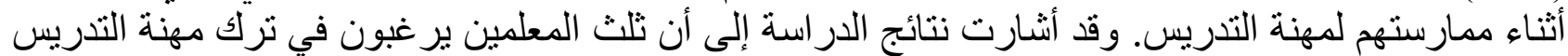

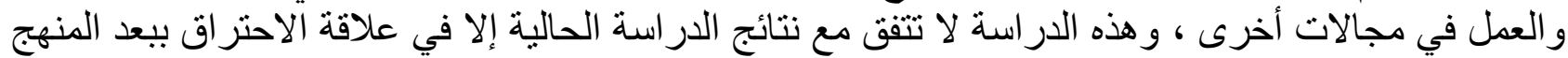

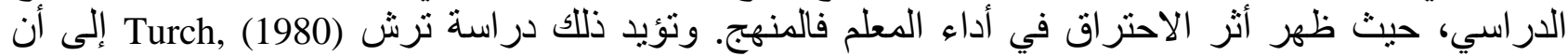

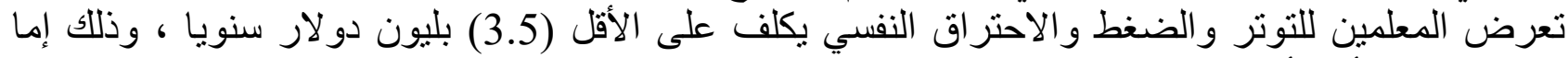
بسبب الغياب، أو الأداء الضعيف.

وتفسر الباحثة عدم وجود علاقة بين مجموع أبعاد الاحتراق النفسي والأداء الوظيفي للمعلم ، أن الاحتراق

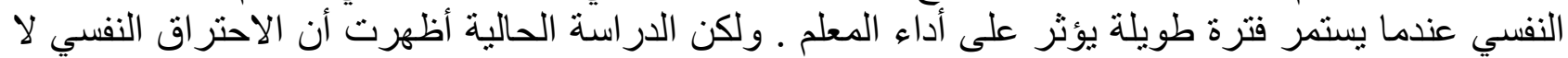

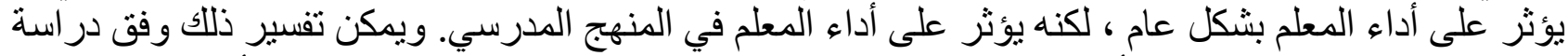

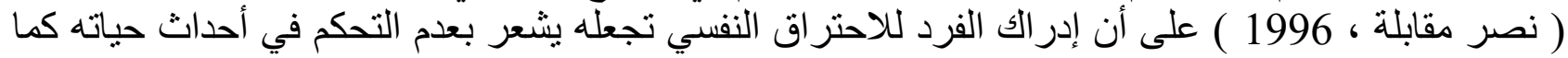

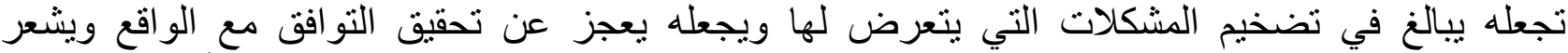
بالاحتر اق النفسي والاحتر اق الجسمي مما يؤدي إلى المرض النفسي ويؤثر على كفاءة المعلم في أدائه لمهنته. بتضح لنا مما تقدم عدم وجود أي علاقة بين الاحتراق النفسي والأداء الوظيفي للمعلم ، إلا في بعد المنهج

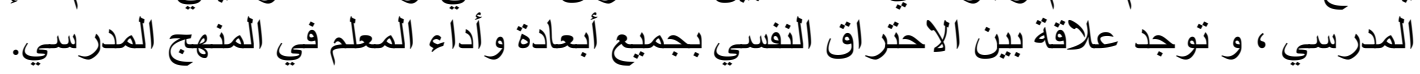

الفرض الرابع: العوامل الايمجرافية وافية أولا: "الإناث أكثر احتر اقا من الذكور الترل

ومن نتائج الدر اسة الحالية يتضح عدم وجود فروق بين المعلمين و المعلمات فيما يتعلق بأجمالي الاحتر اق النفسي

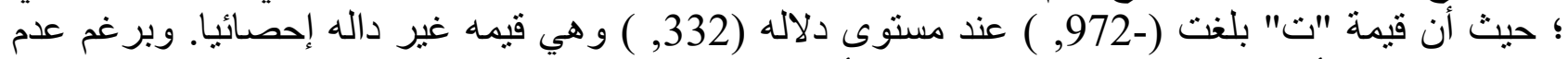

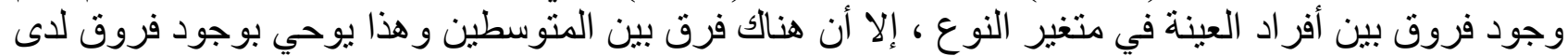

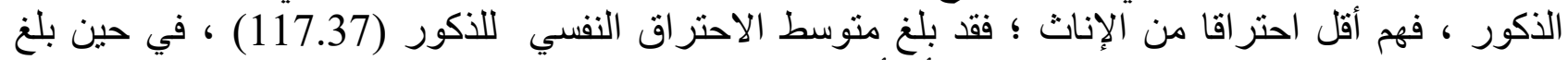

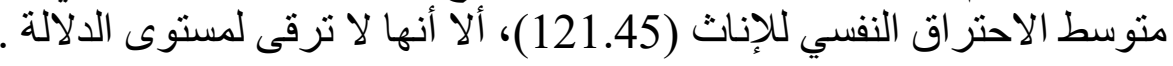

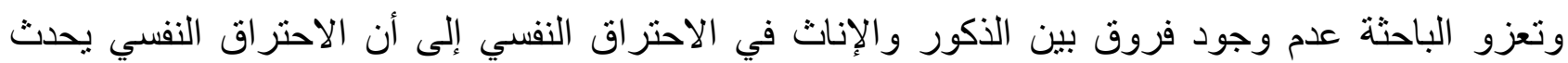

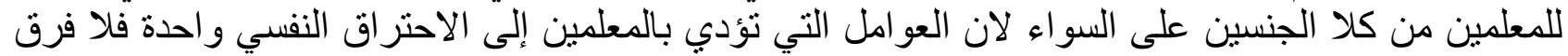

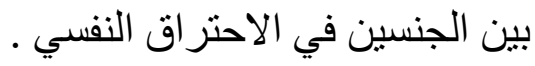
ثانيا: "أصحاب المؤهل الأعلى بكالوريوس - ماجستير أقل احتر اقا من أصحاب مؤ هل الدبلوم " وللتحقق من صحة الفرض استخدمت الباحثة اختبار تحليل التباين "ف"؛ لمعرفة دلالة الفروق بين المتوسطات على النحو الآتي: الاحتراق النفسي؛ بلغت قيمة تحليل التباين اختبار "ف"(4.516) ؛ و هي قيمة دالة إحصائيا. وجاءت النتائج في

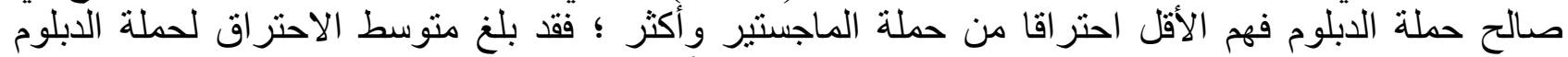
(104.88) ، في حين بلغ متوسط الاحتر اق لحملة الماجستير و أكثر (141.75) .

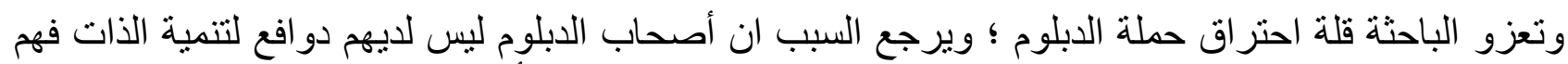

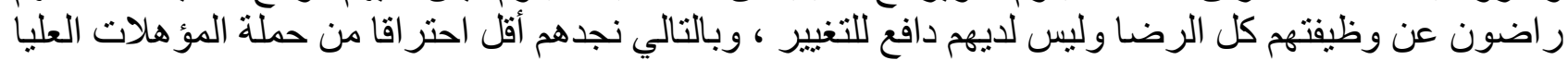

فالتفاوت بين صورة المعلم عن نفسه وتوقعاته المهنية ، و المقارنة بينه وبين الأقران من حملة نفس المؤ هل تزيد

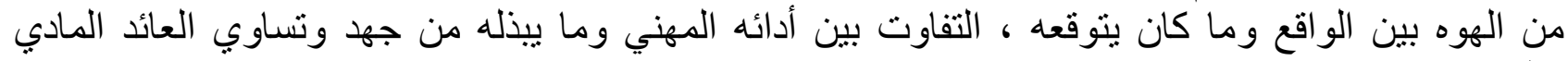

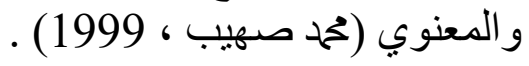

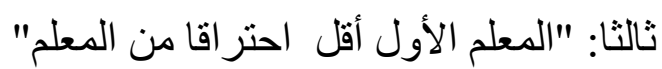
وللتحقت من صحة هذا الفرض استخدمت الباحثة اختبار "ت" 
ومن الجدول السابق يتضح أنه لا توجد فروق معنوية بين درجات الوظيفة الحالية فيما يتعلق بالاحتر اق النفسي ؛

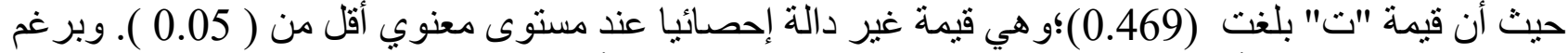

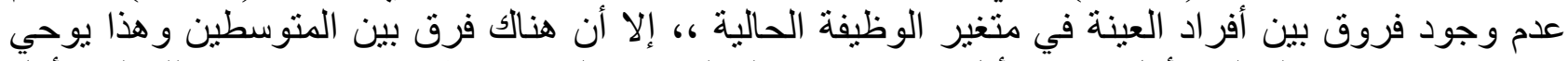

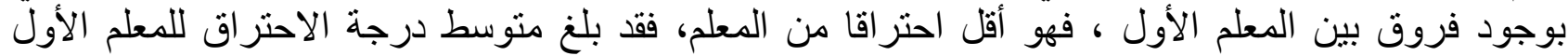

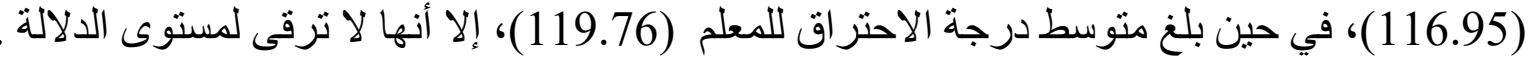

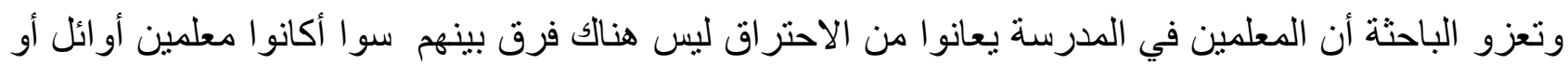

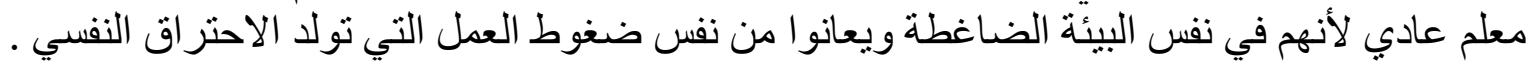

رابعا: "ذوي الخبرة التي تجاوزت (10سنو ات فأكثر) أقل احتر اقا من ذوي الخبرة الأقل". وللتحقق من صحة

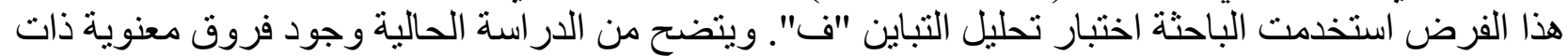
دلالة إحصائية بين سنوات الخبت الخبرة فيما يتعلق بأجمالي الاحتر اق النفسي ؛ حيث بلغت قيمة تحليل التباين "في" (5.324)؛ وهي قيمة دالة إحصائيا

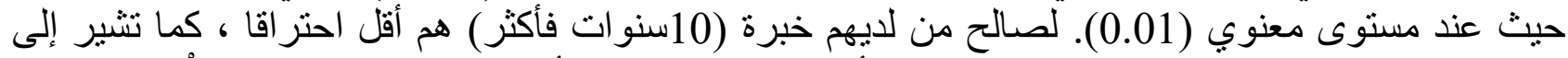

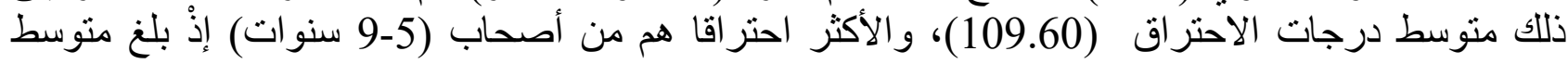
درجات الاحتر اق لها (126.10).

وتعزو الباحثة احتراق المعلمين على اختلاف سنوات خبرتهم في ميدان التدريس وذللك لان طموحاتهم في

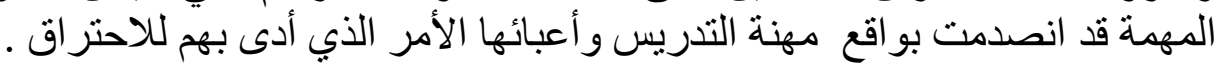
خامسا: " الفئة العمري ( 25-30 ) هي الفئة الأكثر احتر اقا من الفئات العمرية الأخرى ". وللتحقق من صحة هذا الفرض استخدمت الباحثة اختبار تحليل التباين "ف". من نتائج الدر اسة يتضح عدم وجود

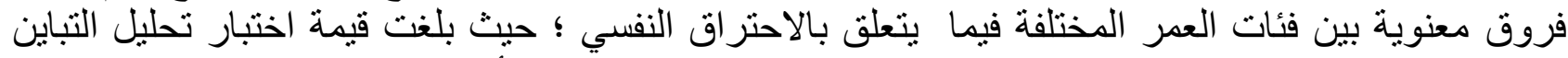

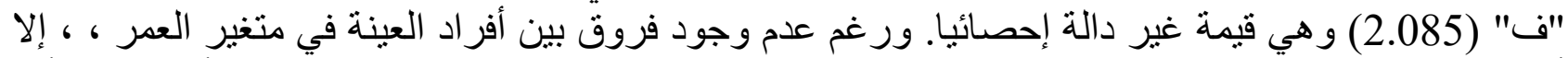

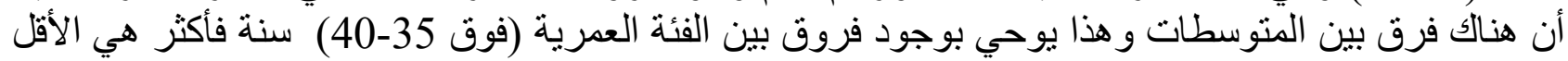

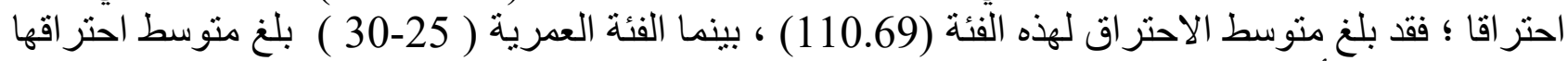

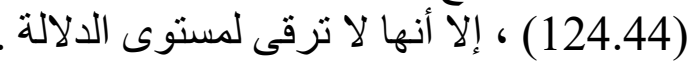

وتعزو الباحثة عدم وجود فروق بين فئات العدر المختلفة للمعلمين في الاحتر اق النفسي يعود إلى مطالب الحياة

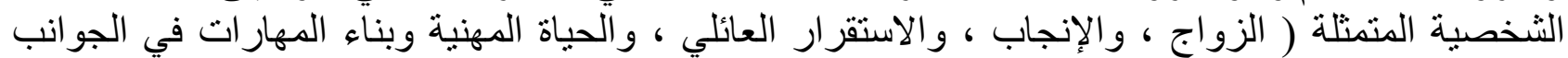

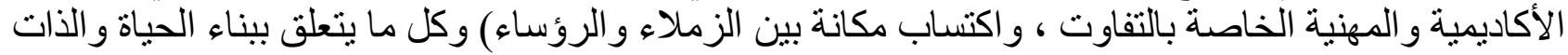

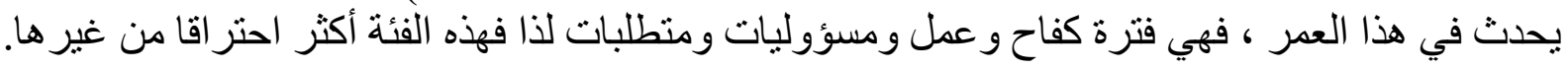
سادسا: "معلمو الحلقة الأولى هم الأكثر احتر اقا من معلمي الحادي عشر و الثاني عشر". للتحقق من صحة هذا الفرض استخدمت الباحثة اختبار تحليل التباين "ف" يتضح عدم وجد فروق معنوية دالة إحصائيا بين المر احل التدريسية فيما يتعلق بالاحتراق النفسي للمعلم ؛ حيث بلغت فيمة اختبار تحليل التباين

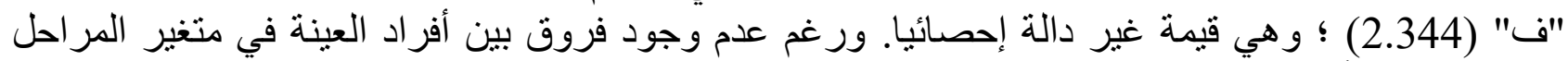

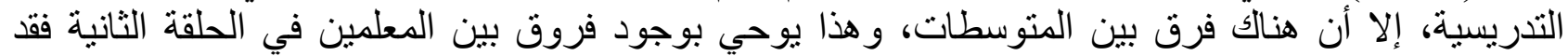

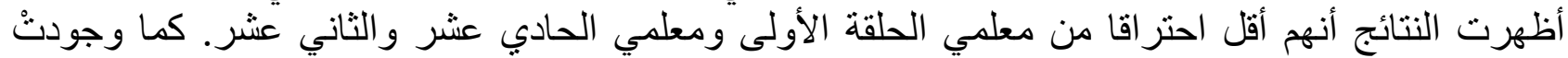

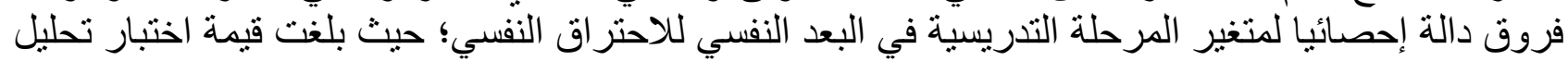
التباين "فوف" (3.153) ؛ و هي قيمة دالة إحصائيا. وقد اختلفت الدر اسة الحالية مع در اسة (Farwell Roberta Jean, 1999) التي أكدت ارتباط مهمة التدريس بخطر

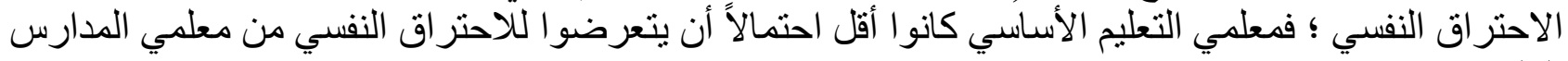
العليا.

وتفسر الباحثة عدم وجود فروق في الاحتراق النفسي لدى المعلمين باختلاف المراحل التعليمية التي بدرسونها ؛ 
لان لكل مرحلة من مر احل التعليم المختلفة مشاقها ومتاعبها. سابعا: " المعلمون المتزوجون هم اقل احتر اقا من الفئات الأخرى".

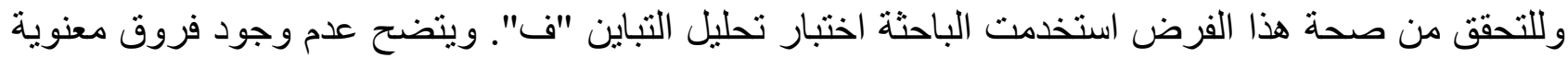

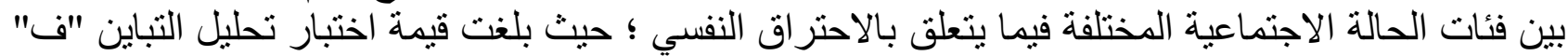

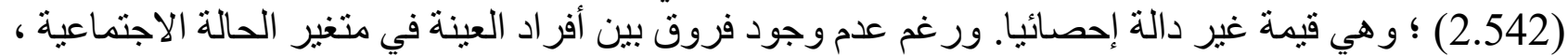

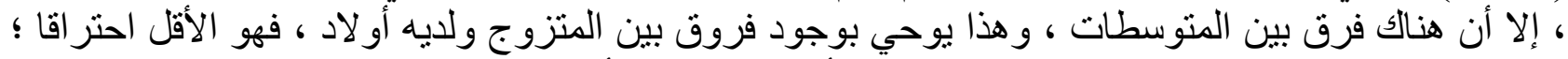

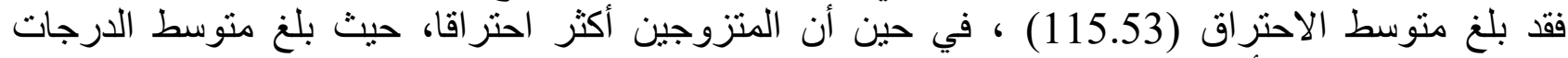

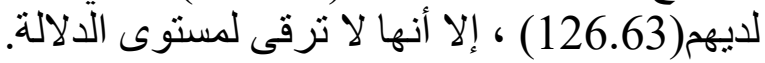

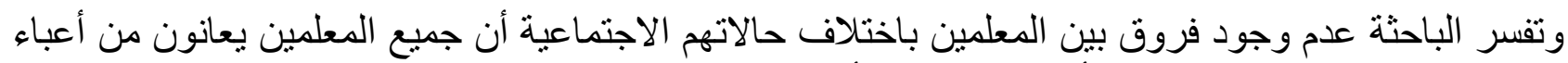

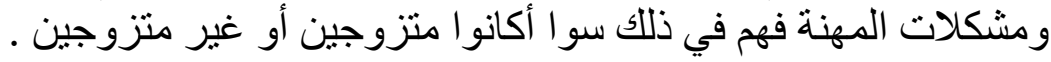

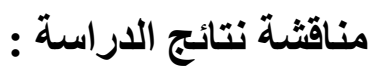

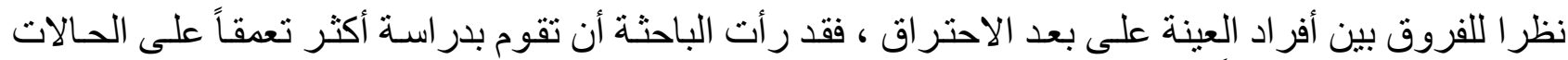

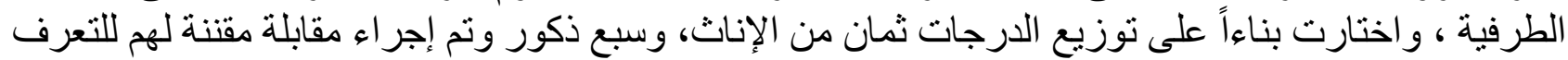

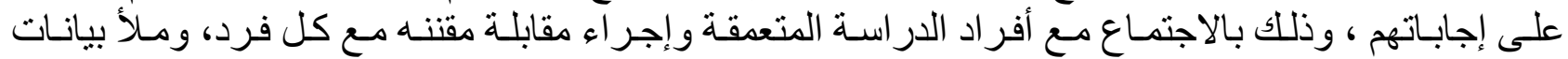

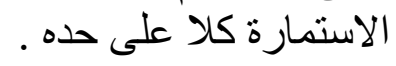

إجراءات تحليل المضمون:

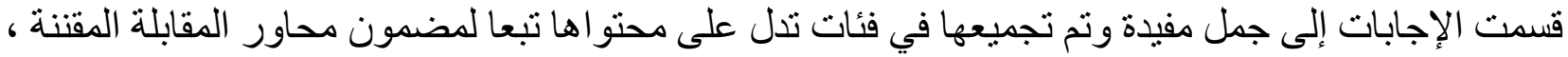
وترفق الباحثة نماذج من تللك المقابلات في ملاحق الدراسة. وكانت نتان نتيجة الدقانة بين الدجمو عتين الاكثر احتر اقا

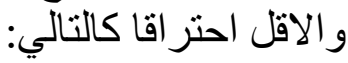
أ. ذكر الأكثر احتر اقا أنه بعد عشر سنوات من الآنه الآن، سيكونون منهكي القوى أو مستقيلون من مهنة التدريس.

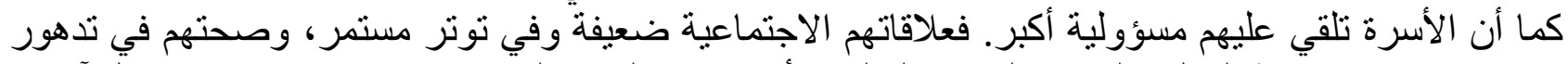

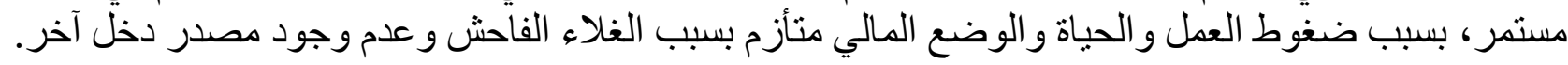

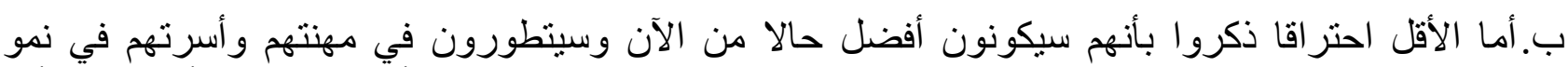

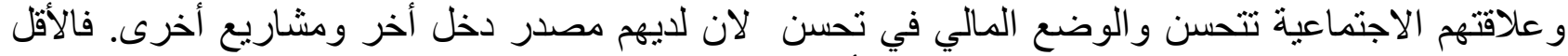

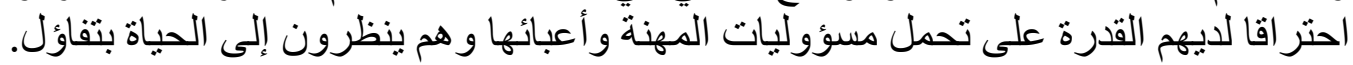

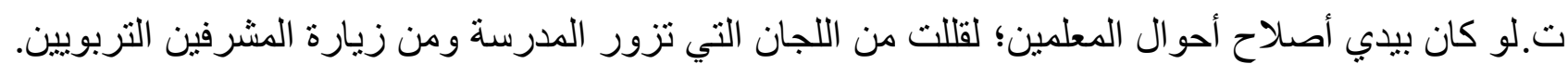

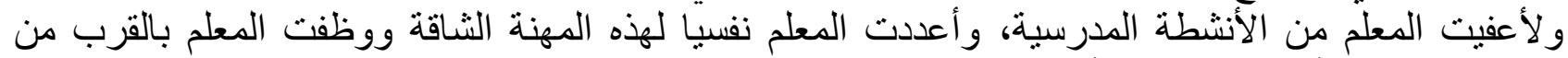
منزلة. كان هذا رأي المجمو عة الأكثر احتر القات.

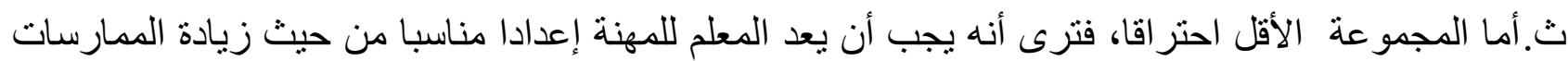

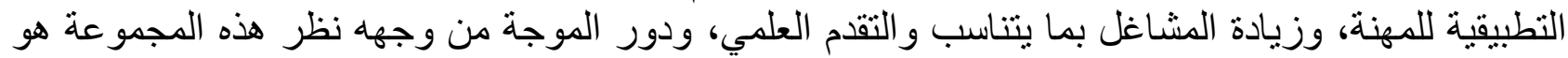

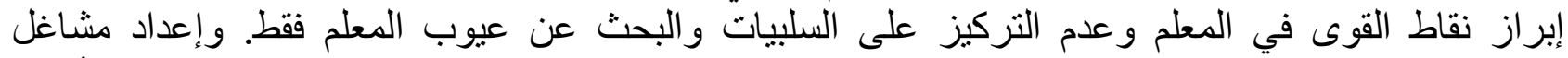

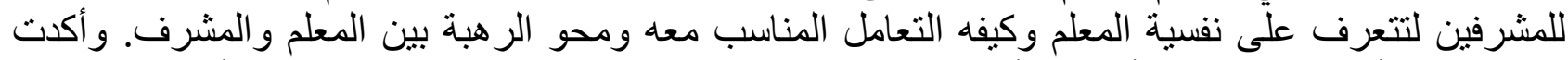

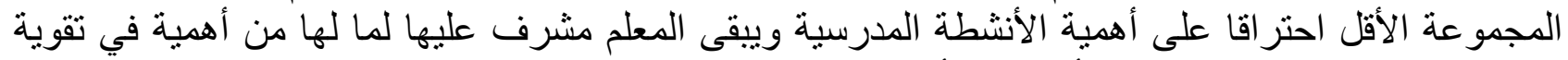

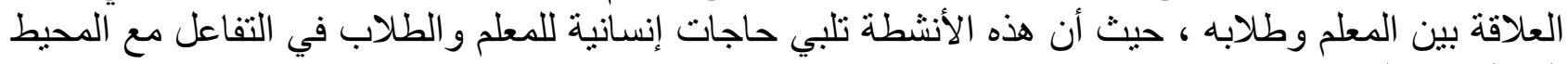

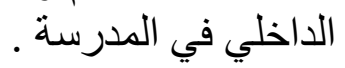

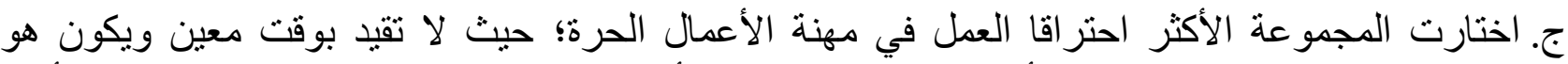

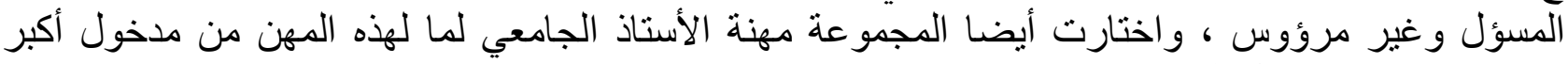

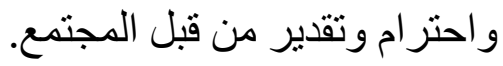


ح. أما المجموعة الأقل احتر اقا فهم بريدون أن يظلوا معلمين ويكملون دراستهم العليا فيما يتعلق بالتدريس .

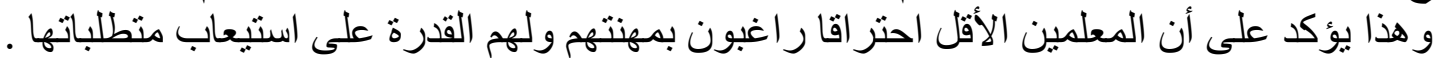
خ. أثنار المعلمون الأكثر احتر اقا أن مهنة التدريس لم تحقق لهم أي طموحات كانو ا يأملون بتحقيقها فنجد هذه أهن

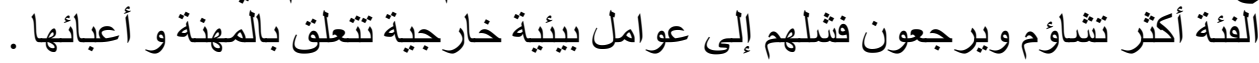

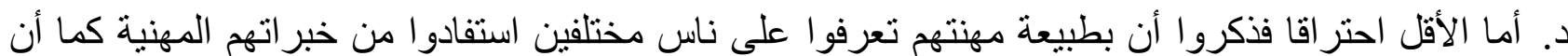

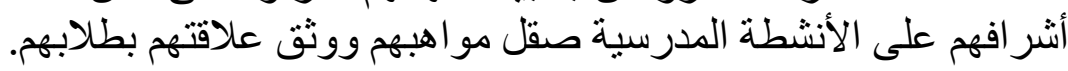

ذ. و أكد المعلمون الأكثر احتر اقا أنهم لا يريدون أن يكونو ا قدوره لأحد أنهم لم يتشابهو ا مع مثلهم الأعلى أبدا

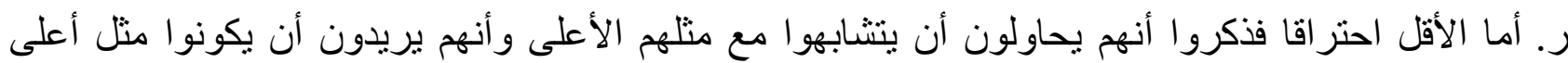

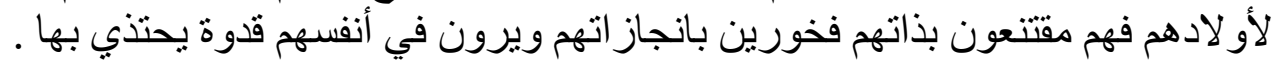

\section{قائمة المراجع العربية:}

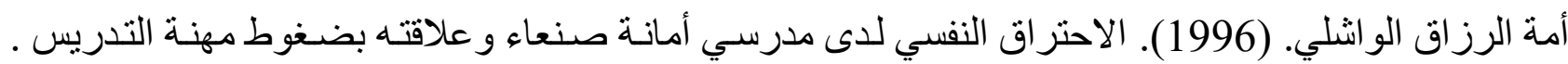
رسالة ماجستير غير منشورة ، جامعة صنعاء ، اليمن .

جاسم ححــ القصير. (1993). المتغير ات المحددة للاحتر اق النفسي لمدرسي المرحلـة المتوسطة ودور التداخل الإرشادي. رسالة دكتور اه غير منشورة، الجامعة المستتصرية، بغداد.

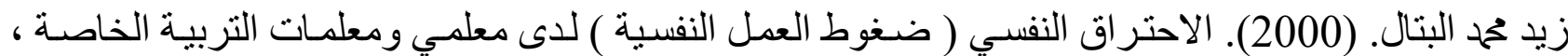

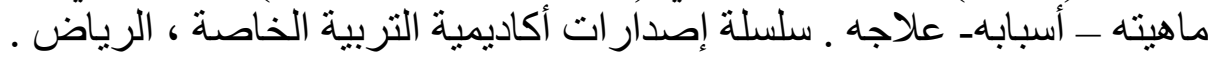

السيد السمادوني. (1991). مقياس الضغوط المهنية للمعلمين ، مكتبة النهضة المصرية ، القاهرة صلاح مر اد و أنور عبد الغفار. (1991). الإنهاك النفسي وعلاقة بالجنس والتخصص و الخبرة التدريسية لمعلمي

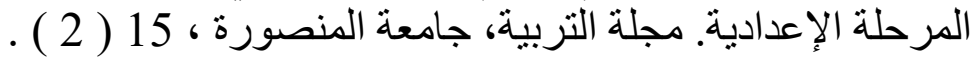
عدنان الفـرح. (2001). الاحتر اق النفس لـدى العـاملين مـع ذوي الاحتياجـات الخاصـة في قطر .مجلـة العلـوم

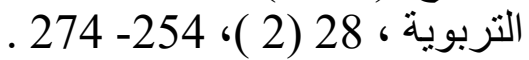

علي عسكر. (2000). ضغوط الحياة وأساليب مو اجنتها ـ القاهرة ، دار الكتاب الحديث. فرج عبد القادر طه وآخرون. (1993). موسو عة علم النفس والتحليل النفسي. ط2، الكويث: دار سعاد الصباح للطباعة.

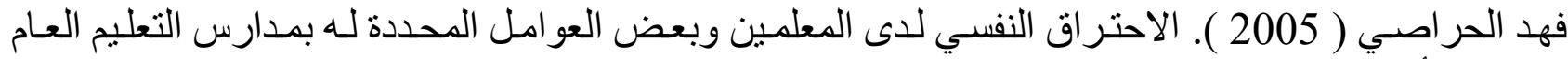
و الأساسي بسلطنة عمان ـ رسالة ماجستير غير منشورة ، كلية التربية ، جامعة السلطان قابوس.

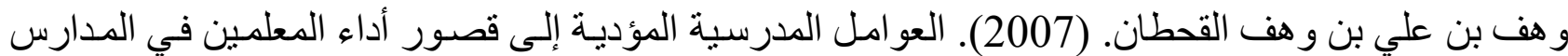

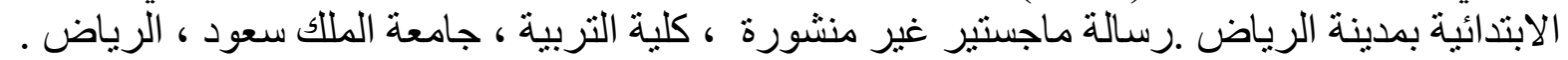
وزارة التربية و التعليم (2008). الكتاب السنوي للإحصـاءات التعليميـة ، المديريـة العامـة للتخطيط و المعلومـات التربوية ، دائرةب الإحصاء و المعلومات ، سلطنة عمان. بطاقة تقويم المعلم. (2008). وزارة التربية والتعليم، سلطنة عمان . عبد المنعم الثناوي، ونصر الله محمد محمود (1991). المهار ات الثخصية في التدريس لدى الطلاب المعلمين

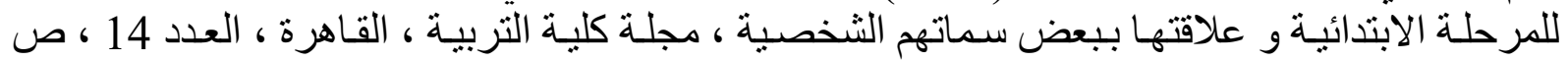

على راشد. (1988). الجامعة و التدريس الجامعي. جدة: دار الثروق ، ص ص 91- 99. 


\section{ARABIC REFERENCES IN ROMAN ALPHABET}

'Umat Alrazaaq Alwashiliu. (1996). Alaihtiraq Alnafsiu Ladaa Madrisii 'Amanat Sanea' Waealaqatih Bidughut Muhnat Altadris . Risalat Majstyr Ghyr Manshurat, Jamieat Sanea', Alyaman .

Jasim Muhamad Alqsyr. (1993). Almutaghayirat Almuhadadat Lilaihtiraq Alnafsii Limudrisi Almarhalat Almutawasitat Wadawr Altadakhul Al'iirshadii. Risalat Dukturah Ghyr Minshurat, Aljamieat Almustansariati, Baghdad.

Zayd Muhamad Albtal. (2000). Alaihtiraq Alnafsiu ( Dughut Aleamal Alnafsia ) Ladaa Muelimiin Wamuelamat Altarbiat Alkhasat , Mahiatah - 'Asbabh- Eilajah . Silsilat 'lisdarat 'Akadimiat Altarbiat Alkhasat , Alriyadh.

Alsyd Alsamaduni. (1991). Miqyas Aldughut Almihniat Lilmuealimin , Maktabat Alnahdat Almisriat, Alqahra

Salah Murad Wa'anwr Eabd Alghafari. (1991). Al'iinhak Alnafsiu Waealaqat Bialjins Waltakhasus Walkhibrat Altadrisiat Limuelimi Almarhalat Al'iiedadiati. Majalat Altarbiat, Jamieat Almansurat, 15 ( 2 ) .

Eadnan Alfrh. (2001). Alaihtiraq Alnafs Ladaa Aleamilin Mae Dhwy Alaihtiajat Alkhasat Fi Qatara.Majalat Aleulum Altarbawiat , 28 (2), 254- 274 .

Eali Easkar. (2000). Dughut Alhayat Wa'asalib Muajahatiha . Alqahrt, Dar Alkitab Alhadith .

Faraj Eabd Alqadir Th Wakharawna. (1993). Mawsueat Eilm Alnafs Waltahlil Alnafsi. Ta2, Alkuayta: Dar Suead Alsabah Liltabaeat.

Fahd Alharrasi ( 2005 ). Alaihtiraq Alnafsiu Ladaa Almuealimin Wbed Aleawamil Almuhadadat Lah Bimadaris Altaelim Aleami Wal'asasii Bisiltanat Eamman . Risalat Majstayr Ghyr Manshurat, Kuliyat Altarbiat , Jamieat Alsultan Qabws.

Wahaf Bin Eali Bin Wahaf Alqahtani. (2007). Aleawamil Almadrasiat Almuadiyat 'lilaa Qusur 'Ada' Almuealimin Fi Almadaris Alaibtidayiyat Bimadinat Alriyad .Risalat Majstyr Ghyr Manshurat, Kuliyat Altarbiat, Jamieat Almalik Sueud, Alriyad .

Wizarat Altarbiat Waltaelim (2008). Alkitab Alsanawia Lil'iihsa'at Altaelimiat, Almudiriat Aleamat Liltakhtit Walmelwmat Altarbawiat, Dayirtib Al'iihsa' Walmelwmat, Saltanat Eaman.

Bitaqat Taqwim Almuelim. (2008). Wizarat Altarbiat Waltaelima, Saltanat Eamman . Eabd Almuneim Alshannawi,

Wanasur Allah Muhamad Mahmud (1991). Almaharat Alshakhsiat Fi Altadris Ladaa Altullab Almuealimin Lilmarhalat Alaibtidayiyat W Ealaqatiha Bibaed Sammatihim Alshakhsiat, Majalat Kuliyat Altarbiat , Alqahrt, Aleadad 14, S 116 .

Ealaa Rashid. (1988). Aljamieat Waltadris Aljamei. Jdt: Dar Alshuruq, S S 91- 99.

\section{REFERENCES}

Antoniou, A, S; Polychroni, F; Vlchakis, A. N. (2006), Gender and age differences in occupational stress and professional burnout between primary and high-school teachers in Greece, Journal-ofManagerial-Psychology. Vol 21 (7) 2006, 682-690.

Fu-ming,-Xu, (2003), A study on teachers' occupational stress and Burnout, Chinese journal of Clinical Psychology. Vol 11(3) Aug 2003, 195-197.

Killian-Jeannie-Gail, (2004), Career and technical education teacher burnout: impact of humor-coping style and job related stress, volume 65-09a of dissertation abstracts international. page 3266

Kokkinos - Constantions (2007). Job stressors, personality and burnout in primary school teachers, British Journal of Educational - Psychology, Vol 77 (1) Mar (229 - 243).

Lee-Ansu, (2004), Occupational stress and burnout among Korean secondary physical educationl techers: testing the job demands control support model (Korean text), Volume $6503 \mathrm{~A}$ of dissertation abstracts international. page 875 .

Masclach C. (1982). Understanding burnout definitional issues in analyzing a complex phenomenon in whiton, $\mathbf{S}$. job stress and burnout research. Theory and intervention perspectives, p. 29, London Beverly, Hills. 
Pinto-Alexandra-Marques; Lima,-Maria-Lusia; Da-Silva, - Adelina-Lopes, (2006), Fuentes de estres, burnout y estrategias de coping en profesores portugueses / Stress sources, burnout and coping among portugese teachers, Revista-de - Psicologia-del - Trabajo - y - de - las-Organizaciones. Vol 21 (1-2) 2005, 125-143.

Platsidou - Maria Agliotis - Loonnis (2008). Burnout, Job Satisfaction and Intructional Assignment Related Sources of stress in Greek Special Education Teacher International Journal of Disability, Development and Education V55 n1 p61 - 76

Wang Wen zeng; Gus, Li Yan (2007): An investigation on occupational stress, teacher burn out and mental health state of primary and middle schools teacher and the relations among them - Chinese Journal of clinical psychology (146

Spiggle-jo-anne-Blackmon, 2003 : Relationship between teacher performance and student growth outcomes in a school district in north carolina's public schools' fifth grades, North Carolina-StateUniversity (0155) p. 184.

Teel-Shanna-Rae, 2003 : Relationships among perceived organizational support, teacher efficacy, and teacher performance , Alliant-International-University-San-Diego (1389), p. 156.

Bowers-Mary-Beth, 2006 : The impact of teacher characteristics on teacher performance and student achievement : A Jud study of principals and superintendents, University-of-Virginia (0246), p. 180

Moore-Kelly,2004 : Diagnosing student's reading strengths and needs and planning their subsequent differentiated instruction : A comparative investigation 